\title{
Doublecortin-like Kinase 1 Regulates $\alpha$-Synuclein Levels and Toxicity
}

\author{
Gabriel E. Vázquez-Vélez, ${ }^{1,2,4}$ Kristyn A. Gonzales, ${ }^{1,3}$ Jean-Pierre Revelli, ${ }^{1,3}$ Carolyn J. Adamski, ${ }^{1,3,8}$ Fatemeh Alavi Naini, ${ }^{1,3}$ \\ (D)Aleksandar Bajic, ${ }^{1,3}$ Evelyn Craigen, ${ }^{1,3}$ Ronald Richman, ${ }^{1,3,8}$ Sabrina M. Heman-Ackah, ${ }^{6}$ Matthew J.A. Wood, ${ }^{6,7}$ \\ (D) Maxime W.C. Rousseaux, ${ }^{1,3}$ and (D)Huda Y.Zoghbi ${ }^{1,2,3,4,5,8}$ \\ ${ }^{1} J a n$ and Dan Duncan Neurological Research Institute at Texas Children's Hospital, Houston, Texas 77030, ${ }^{2}$ Program in Developmental Biology, \\ ${ }^{3}$ Department of Molecular and Human Genetics, ${ }^{4}$ Medical Scientist Training Program, ${ }^{5}$ Department of Pediatrics, Baylor College of Medicine, Houston, \\ Texas 77030, ${ }^{6}$ Department of Physiology, Anatomy and Genetics, University of Oxford, Oxford OX1 3QX, United Kingdom, ${ }^{7}$ Department of Paediatrics, \\ University of Oxford, Oxford OX3 9DU, United Kingdom, and ${ }^{8}$ Howard Hughes Medical Institute, Houston, Texas 77030
}

$\alpha$-Synuclein ( $\alpha$-Syn) accumulation is a pathological hallmark of Parkinson's disease. Duplications and triplications of SNCA, the gene coding for $\alpha$-Syn, cause genetic forms of the disease, which suggests that increased $\alpha$-Syn dosage can drive PD. To identify the proteins that regulate $\alpha$-Syn, we previously performed a screen of potentially druggable genes that led to the identification of 60 modifiers. Among them, Doublecortin-like kinase 1 (DCLK1), a microtubule binding serine threonine kinase, emerged as a promising target due to its potent effect on $\alpha$-Syn and potential druggability as a neuron-expressed kinase. In this study, we explore the relationship between DCLK1 and $\alpha$-Syn in human cellular and mouse models of PD. First, we show that DCLK1 regulates $\alpha$-Syn levels post-transcriptionally. Second, we demonstrate that knockdown of Dclk1 reduces phosphorylated species of $\alpha$-Syn and $\alpha$-Syn-induced neurotoxicity in the SNc in two distinct mouse models of synucleinopathy. Last, silencing DCLK1 in human neurons derived from individuals with SNCA triplications reduces phosphorylated and total $\alpha$-Syn, thereby highlighting DCLK1 as a potential therapeutic target to reduce pathological $\alpha$-Syn in disease.

Key words: $\alpha$-synuclein; DCLK1; disease models; protein levels

\section{Significance Statement}

DCLK1 regulates $\alpha$-Syn protein levels, and Dclk1 knockdown rescues $\alpha$-Syn toxicity in mice. This study provides evidence for a novel function for DCLK1 in the mature brain, and for its potential as a new therapeutic target for synucleinopathies.

\section{Introduction}

Parkinson's disease (PD) is a common neurodegenerative condition affecting $\sim 6.1$ million people worldwide (Dorsey and Elbaz,

Received May 10, 2019; revised Oct. 1, 2019; accepted 0ct. 25, 2019.

Author contributions: G.E.V.-V., K.A.G., J.-P.R., C.J.A., A.B., E.C., M.W.C.R., and H.Y.Z. designed research; G.E.V.V., K.A.G., J.-P.R., C.J.A., F.A.N., A.B., E.C., R.R., and M.W.C.R. performed research;G.E.V.-V., J.-P.R., and E.C. analyzed data; G.E.V.-V. and H.Y.Z. wrote the first draft of the paper; G.E.V.-V., K.A.G., S.M.H.-A., M.J.A.W., M.W.C.R., and H.Y.Z. edited the paper; G.E.V.-V. and H.Y.Z. wrote the paper.

This work was supported in part by the Huffington Foundation and the Howard Hughes Medical Institute to H.Y.Z. H.Y.Z. was also supported by UCB Pharma and the Hamill Foundation. M.W.C.R. was supported by Parkinson's Foundation Stanley Fahn Junior Faculty Award Grant PF-JFA-1762. S.M.H.-A. and M.J.A.W. were supported by Cure Parkinson's Trust and John Fell OUP Research Fund. We thank the Gordon and Mary Cain Pediatric Neurology Research Foundation Laboratories for allowing us access to their stereological microscope. The IDDRC Microscopy Core (National Institutes of Health U54 HD083092 from the Eunice Kennedy Shriver National Institute of Child Health and Human Development), the RNA In Situ Hybridization Core at BCM (with expert assistance of Cecilia Ljungberg and funding from National Institutes of Health S100D016167 and U54 HD083092), and Baylor College of Medicine Gene Vector Core were used for this project. We also used the WA09 human ESC line (H9 ESC) derived by Dr. James Thomson and distributed by WiCell Research Institute under SLA agreement. We thank Vitaliy Bondar, Won-Seok Lee, James Orengo, Joseph McInnes, and all members of the H.Y.Z. laboratory for important discussions and critical feedback on the manuscript; and Marie-Françoise Chesselet (UCLA) for the gift of the Thy1- $\alpha$-Syn- "Line 61" mice, as well as the National Institute of Neurological Disorders and Stroke human and cell data repository for patient iPSCs.

The authors declare no competing financial interests.
2018). PD is characterized by the death of the dopaminergic neurons of the SNc and the accumulation of the presynaptic protein $\alpha$-Synuclein ( $\alpha$-Syn) (Spillantini et al., 1998; Burré et al., 2018). Although the pathogenic mechanism(s) of PD remain(s) elusive, there is evidence that suggests that increased $\alpha$-Syn levels can drive PD. First, humans with duplications and triplications of the SNCA locus (encoding $\alpha$-Syn) develop autosomal dominant PD (Singleton et al., 2003; Chartier-Harlin et al., 2004; Ibáñez et al., 2004). Importantly, $\alpha$-Syn levels correlate with the severity of symptoms (Devine et al., 2011). Second, some single nucleotide polymorphisms in regulatory regions of SNCA increase PD risk and SNCA transcript levels (Soldner et al., 2016). Third, the effect of drugs on SNCA transcript load directly correlates with PD risk

Correspondence should be addressed to Huda Y. Zoghbi at hzoghbi@bcm.edu.

S.M. Heman-Ackah's present address: Department of Neurosurgery, University of Pennsylvania, Philadelphia 19104, PA

M.W.C. Rousseaux's present address: University of Ottawa Brain and Mind Research Institute, Department of Cellular and Molecular Medicine, University of Ottawa, Ottawa, Ontario K1H 8M5, Canada.

https://doi.org/10.1523/JNEUROSCI.1076-19.2019

Copyright $\odot 2020$ the authors 
at the epidemiological level (Mittal et al., 2017). Furthermore, haploinsufficiency in $G B A 1$ increases PD risk due to defects in the lysosomal clearance of $\alpha$-Syn (Mazzulli et al., 2011). Despite this, only a few regulators of $\alpha$-Syn levels have been identified previously. These include transcriptional regulators (ZSCAN21, ZSCAN219, GATA-1, and GATA-2) (Scherzer et al., 2008; Clough et al., 2009; Dermentzaki et al., 2016; Lassot et al., 2018) as well as a handful of post-translational regulators, such as Pololike kinase 2 (Oueslati et al., 2013), NEDD4 (Tofaris et al., 2011), USP9X (Rott et al., 2011), and TRIM28 (Rousseaux et al., 2016). How well most of these modulators would serve as therapeutic targets remains an open question. NEDD4 and USP9X have not been tested in vivo, and the beneficial effect of PLK2 requires increasing its kinase activity, which is pharmacologically challenging. To address the scarcity in modulators of $\alpha$-Syn levels, we performed an shRNA screen on 7787 potentially druggable genes (Rousseaux et al., 2018), and identified 60 new regulators of $\alpha$-Syn levels. We selected 10 for further verification in human neurons and in the mouse brain. Doublecortin-like kinase 1 (DCLK1) emerged as the most promising regulator because it is a neuron expressed kinase, and it was also identified in a separate orthogonal siRNA screen targeting the kinome (Rousseaux et al., 2016).

DCLK1 was originally discovered based on its homology to Doublecortin (DCX) (Burgess et al., 1999; Silverman et al., 1999), a gene essential for cortical development and whose mutations lead to subcortical band heterotopia (des Portes et al., 1998; Gleeson et al., 1999; Horesh et al., 1999). Further studies since then have revealed that the DCLK1 protein is localized to the somatodendritic compartment (Shin et al., 2013) and is composed of a microtubule binding segment (DCX domains) and a serine threonine kinase domain separated by a PEST-rich sequence (Patel et al., 2016). The DCX domains allow DCLK1 to bind and polymerize microtubules (Lin et al., 2000), and to guide kinesin 3-coated vesicles to the dendritic compartment (Lipka et al., 2016). The function of the kinase domain is less well characterized. MAP7D1, a microtubule binding protein, DCX, and DCLK1 itself are the only known phosphorylation targets of DCLK1 (Koizumi et al., 2017). Additionally, little is known about the function of DCLK1 in the adult brain.

We decided to pursue the mechanism by which DCLK1 regulates $\alpha$-Syn levels and determine the effect of Dclk1 knockdown in mouse models of synucleinopathy. We found that DCLK1 regulates $\alpha$-Syn protein levels through its kinase domain independently of its catalytic activity, and that Dclk1 knockdown reduces phosphorylated species of $\alpha$-Syn (pS129) (Fujiwara et al., 2002) in the Thy1- $\alpha$-Syn- "Line 61" (Rockenstein et al., 2002) model of synucleinopathy and $\alpha$-Syn-induced dopaminergic neuron toxicity in an adeno-associated virus (AAV)-mediated SNCA overexpression mouse model. Moreover, DCLK1 knockdown reduces $\alpha$-Syn levels in SNCA triplication patient neurons. Thus, we reveal an important function of DCLK1 in the adult brain, and highlight its important role regulating $\alpha$-Syn levels.

\section{Materials and Methods}

Protein extraction, SDS-PAGE, and Western blotting for measuring protein levels

Protein extraction. To extract protein from AAV-injected brains, we dissected and flash frozen (in liquid nitrogen) the posterior cortex and hippocampus from mice anesthetized at 3 weeks old (WT mice) or 2 months old (transgenic mice). Frozen tissue was thawed on ice and ground using a motor-powered pestle in $1 \times$ PEPI buffer (5 mM EDTA, PBS, $10 \mathrm{ml} / \mathrm{g}$ ) supplemented with protease and phosphatase inhibitors ( $1 \times$ GenDEPOT, P3100-100, P3200-020); $125 \mu$ l of the homogenate was saved for RNA extraction (see RNA extraction and qPCR), the rest was mixed $1: 1$ with $2 \times$ RIPA ( $100 \mathrm{~mm}$ Tris, $\mathrm{pH} 7.5,300 \mathrm{~mm} \mathrm{NaCl}, 0.2 \%$ SDS, $1 \%$ sodium deoxycholate; $\%$ NP-40, 10 mm EDTA, pH 8.0) buffercontaining protease and phosphatase inhibitors $(1 \times)$. The lysates were then vortexed and incubated on ice for $20 \mathrm{~min}$, before being spun down at $13,000 \mathrm{rpm}$ for $20 \mathrm{~min}$.

SDS-PAGE and Western blotting. Protein samples were loaded on either 10- or 15-well Nupage $4 \%-12 \%$ Bis-Tris gels (Invitrogen, NP0335BOX,NP0336BOX), or 17-well BOLT 4\%-12\% Bis-Tris gels (NW04127BOX). Gels were run in MES buffer (50 mM MES, $50 \mathrm{~mm}$ Tris base, $0.1 \%$ SDS, 1 mM EDTA, pH 7.3), and proteins were then transferred onto Protran Premium NC Nitrocellulose membranes $(0.2 \mu \mathrm{m}$ pore, GE Healthcare, 45004004) in Tris glycine buffer (25 mu Tris, $190 \mathrm{~mm}$ glycine) supplemented with $10 \%$ methanol at 0.34 amps for $1 \mathrm{~h}$.

After being transferred, membranes were blocked in $5 \%$ milk in TBS-T for $1 \mathrm{~h}$ and probed with one of the following primary antibodies in 5\% milk overnight: anti $\alpha$-Syn (C20, Santa Cruz Biotechnology, sc-7011-R, RRID:AB_2192953) 1/500, anti-human $\alpha$-Syn (MJFR1, Abcam, ab13850, RRID:AB_2537217) 1/1000, anti- $\alpha$ Syn (Clone 42, BD Biosciences, 610787, RRID:AB_398108) 1/2000, anti-pS129 $\alpha$-Syn (Abcam, ab51253, RRID:AB_869973) 1/500, anti-Dclk1 (Abcam, ab31704, RRID:AB_873537) 1/500, anti- $\beta$ III tubulin (Millipore Sigma, T8578, RRID:AB_1841228) 1/10000, anti-vinculin (Millipore Sigma, V9131, RRID:AB_477629) 1/10000, anti-Flag (M2, Millipore Sigma, F1804, RRID:AB_262044) 1/1000, anti-APP (22C11, Millipore, MAB348, RRID:AB_94882) 1/2000, and anti-Tau (Dako, A0024, RRID:AB_10013724) 1/5000. The next day, membranes were probed with secondary antibodies for $1 \mathrm{~h}$. For chemiluminescent Western blotting, donkey anti-mouse HRP-conjugated antibody (Jackson ImmunoResearch Laboratories, 715-035-150, RRID: AB_2340770) or goat anti-rabbit HRP-conjugated antibody (BioRad, 170-5046, RRID:AB_11125757) were used 1/10,000 in 5\% milk. For fluorescent Western blotting, IRDye 680RD goat anti-rabbit IgG (LI-COR Biosciences, 926-6807, RRID:AB_10956166) or IRDye 800CW goat anti-mouse IgG (LI-COR Biosciences, 926-32210, RRID: AB_621842) were diluted 1/10,000 in LI-COR Odyssey TBS blocking buffer (927-50003). The membranes were imaged on an Imager 600 (GE Healthcare, 29083461) using the ECL Prime Reagent (GE Healthcare, 45010090) for chemiluminescence or on an Odyssey imager for fluorescent blots (LI-COR Biosciences). All Western blot data were quantified using ImageStudioLite (LI-COR Biosciences).

\section{RNA extraction and cDNA production}

We used PEPI buffer to homogenize the tissue (see Protein extraction). RNA from mouse brain was then extracted using TRIzol (Invitrogen, catalog \#15596-026), and total RNA was purified using the miRNeasy micro kit (QIAGEN, 217004) according to the manufacturer's instructions. cDNA was generated using the QuantiTect Reverse Transcription Kit (QIAGEN, 205313) according to the manufacturer's instructions.

\section{$q P C R$}

qPCR was performed with PowerUp SYBR Master Mix (Thermo Fisher Scientific, A25777) on a Bio-Rad CFX96 instrument. Dclk1 primers specific for exon junctions of either the full-length, kinase domain, or total transcripts (see below); $10 \mathrm{ng}$ of cDNA was used in technical triplicate for each primer pair. The average dCt was calculated from biological triplicate values, and the relative abundance of the measured transcripts was determined using the ddCT method (Pfaffl, 2001). For all experiments in mice, Ppia (see below) was used to normalize ddCT values (Kim et al., 2014). For all experiments in human neurons, TUBB3 (a well-known marker of neurons) (Latremoliere et al., 2018) was used to normalize ddCT values.

Mouse primers are as follows: Dclk1 All transcripts forward: 5' CTGGGTTAATGATGATGGTCTCC-3'; Dclk1 all transcripts reverse: 5'-ACAGAAACTCCTGCTGCAGT-3'; Dclk1 full-length forward: $5^{\prime}$ TCCTTCGAGCAGGTTCTCAC-3'; Dclk1 full-length reverse: $5^{\prime}$-GA AGGCACATCACCTGCTTC-3'; Dclk1 kinase domain forward: $5^{\prime}$ GAAGTTAATGGAACCCCTGGTAG-3'; Dclk1 kinase domain reverse: 5'-GAGAGATCCTCTGCTTCCGC-3'; Snca forward: 5'-GTGACAA CAGTGGCTGAGAAGAC-3'; Snca reverse: 5'-GGTACCCCTCCT 


\section{shLuciferase $\square$ shDclk1}

A

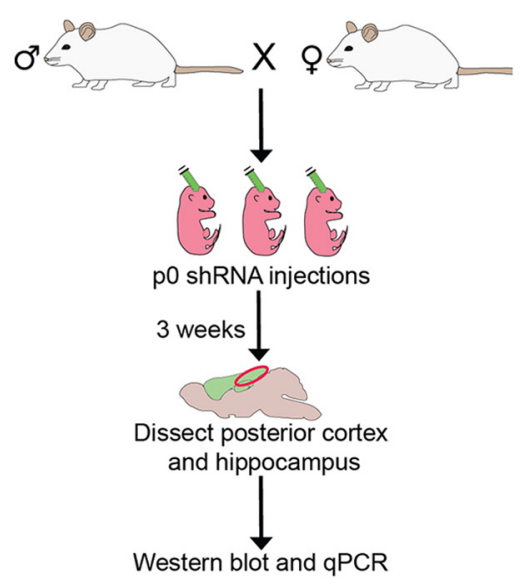

D

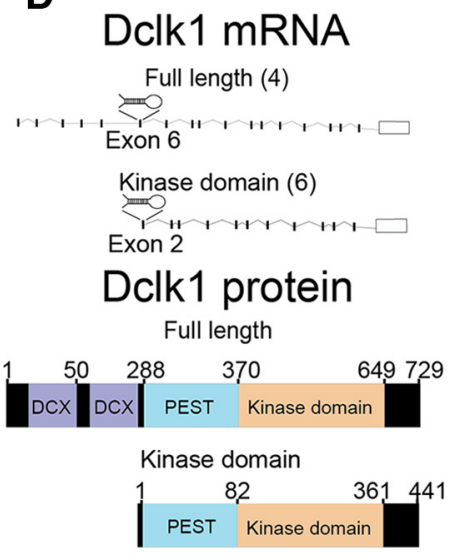

B
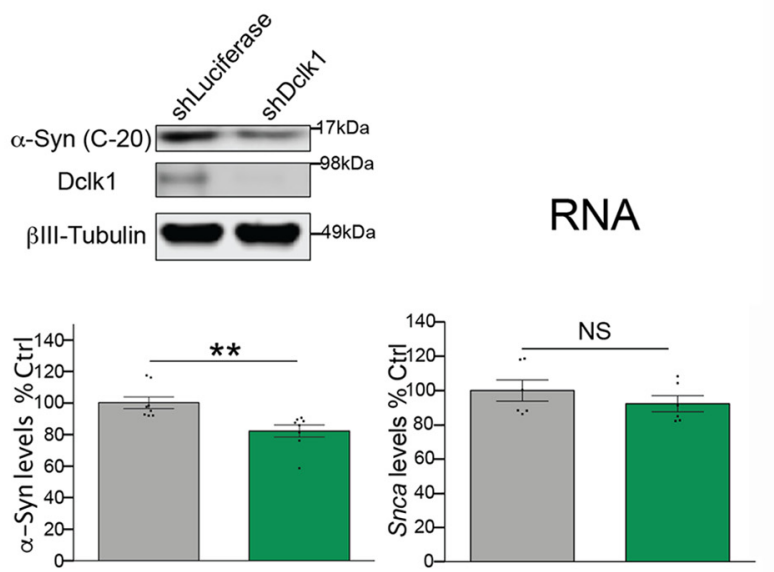

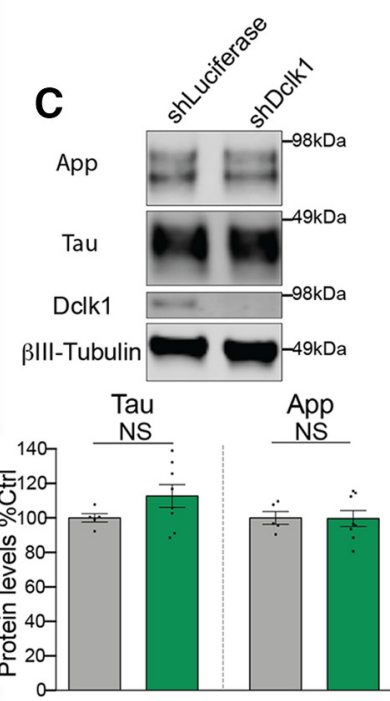

$\mathbf{E}$
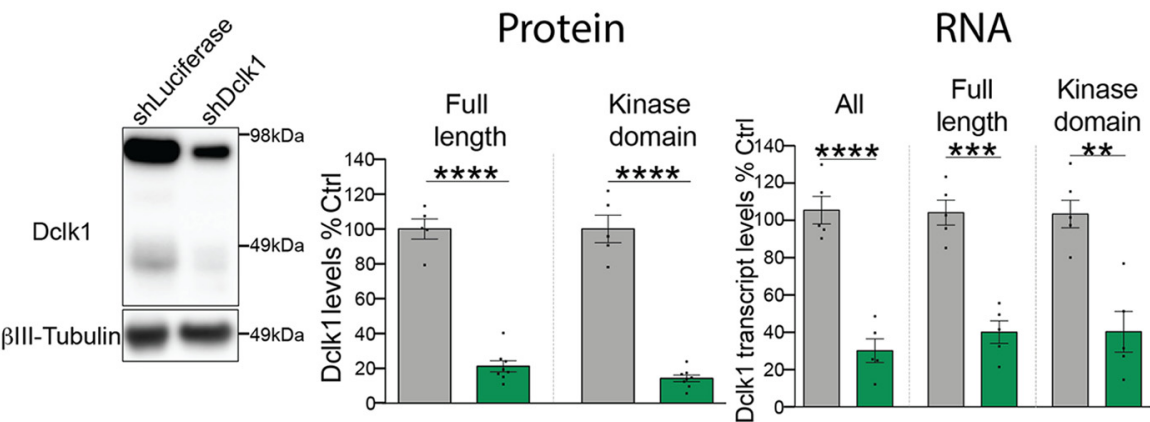

Figure 1. Dclk1 regulates $\alpha$-Syn levels post-transcriptionally. $A$, Diagram of the experimental strategy. CFW WT females were bred to male WT mice. Neonatal intraventricular injections of AAVs carrying shRNA were performed on their pups, and tissue from the injected mice was collected 3 weeks following injection. The posterior cortex and associated hippocampus were dissected for Western blotting and qPCR. B, Western blot $(t=3.376, p=0.0045)$ and (RNA) $(t=0.9981, p=0.3418)$ for $\alpha$-Syn protein (C-20) and transcript levels after Dclk1 knockdown in the mouse brain. Each data point represents individual animals. $C$, Tau $(t=1.457, p=0.1713)$ and App $(t=0.05485, p=0.1713)$ protein levels measured by Western blot after $D c l k 1$ knockdown in the brain. Each data point represents individual animals. $D$, Diagram of $D c k 1$ transcripts and protein products expressed in the mouse brain. Numbers represent how many transcripts of each kind are expressed. The site targeted by the shRNA (exon 6 in full-length transcript, exon 2 in shortened products) is shown. $E$, Dclk1 protein and transcript levels in mouse brains after Dclk 1 knockdown measured by Western blotting and qPCR, respectively. Protein full-length, $t=9.706, p=0.0002 ;$ protein kinase domain, $t=4.042, p=0.0099 ;$ RNA all, $t=7.726, p<0.0001 ;$ RNA full-length, $t=4.798$, $p=0.0001$. Error bars indicate SEM. Student's $t$ test: NS $\geq 0.05 ;^{* *} p \leq 0.01 ;{ }^{* * *} p \leq 0.001 ;{ }^{* * * *} p \leq 0.0001$.

CACCCTTG-3'; Ppia forward: 5'-GCATACAGGTCCTGGCATCT-3'; Ppia reverse: 5'-CCATCCAGCCATTCAGTCTT-3'.

Human primers are as follows: SNCA forward: $5^{\prime}$-TGTTCTCTAT GTAGGCTCCA-3'; SNCA reverse: 5'-ACTTGCTCTTTGGTCTTCTC3'; TUBB3 forward: 5'-ATCAGTGATGAGCATGGCA-3'; TUBB3 reverse: $5^{\prime}$-ACTTGTGAGAAGAGGCCTC-3'.

\section{Immunoprecipitation}

In vivo immunoprecipitation (IP). For in vivo IP, mice of both sexes were anesthetized with isoflurane. After anesthesia, cervical dislocation was performed, and the brain was dissected out of the skull. The brain was then cut in half and flash frozen in liquid nitrogen. Each brain half was lysed in NETT ( $170 \mathrm{~mm} \mathrm{NaCl}, 1 \mathrm{~mm}$ EDTA, 50 mu Tris, pH 7.4, 0.5\% Triton X-100) buffer with protease and phosphatase inhibitors using Dounce homogenizers. The lysates were then incubated on ice for $20 \mathrm{~min}$ and spun down at $13,000 \mathrm{rpm}$ for $20 \mathrm{~min}$ at $4^{\circ} \mathrm{C} ; 50 \mu$ lof cleared lysate was kept for input; $400 \mu \mathrm{l}$ of each lysate was conjugated with either normal rabbit IgG (Millipore, 12-370, RRID:AB_145841) or DCLK1 antibody (Abcam, ab31704, RRID:AB_873537) for $2 \mathrm{~h}$. Meanwhile, $30 \mu \mathrm{l}$ of Protein A Dynabeads (Invitrogen, 100-02D) were washed 3 times in 500 $\mu l$ of NETT buffer. Each lysate/antibody complex was then added to the beads and incubated for $30 \mathrm{~min}$ at $4^{\circ} \mathrm{C}$. The beads were then washed 5 times with $1 \mathrm{ml}$ of NETT buffer, and the samples were resuspended and eluted in the same NETN:Laemmli buffer mixture as described above. The samples were loaded onto an SDS-PAGE gel as described above.

IP in cells. For experiments in cells, HEK293T cells (ATCC, CRL-3216) were seeded on 6-well dishes at 500,000 cells/well (Corning, 08-772-1B). The next day, the cells were transfected with $250 \mathrm{ng}$ of either empty vector or DCLK1-3XFlag using MIRUS TransIT-293 reagent (MIR 2706) according to the manufacturer's instructions. At $48 \mathrm{~h}$ after transfection, 10 $\mu$ l of Protein A Dynabeads (Invitrogen, 100-02D) per sample was washed 3 times in NETT buffer supplemented with $1 \times$ protease and phosphatase inhibitor cocktails (Genedepot, P3100-100, P3200-020). They were then incubated with $1 \mu \mathrm{g}$ of either anti- $\alpha$-Syn rabbit polyclonal (C-20, Santa Cruz Biotechnology, sc-7011-R, RRID:AB_2192953) or normal rabbit IgG (Millipore, 12-370, RRID:AB_145841) for $2 \mathrm{~h}$ at $4^{\circ} \mathrm{C}$. The beads were then washed 3 times. During the antibody-bead conjugation, cells were resuspended in PBS and spun down at $5000 \mathrm{rpm}$ for $5 \mathrm{~min}$. The cell pellet was gently resuspended in NETT buffer supplemented with protease and 
A
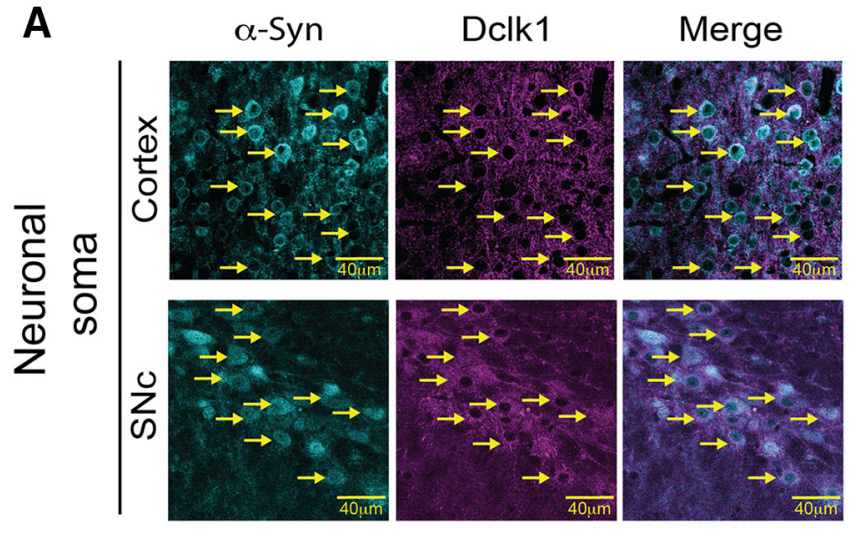

B
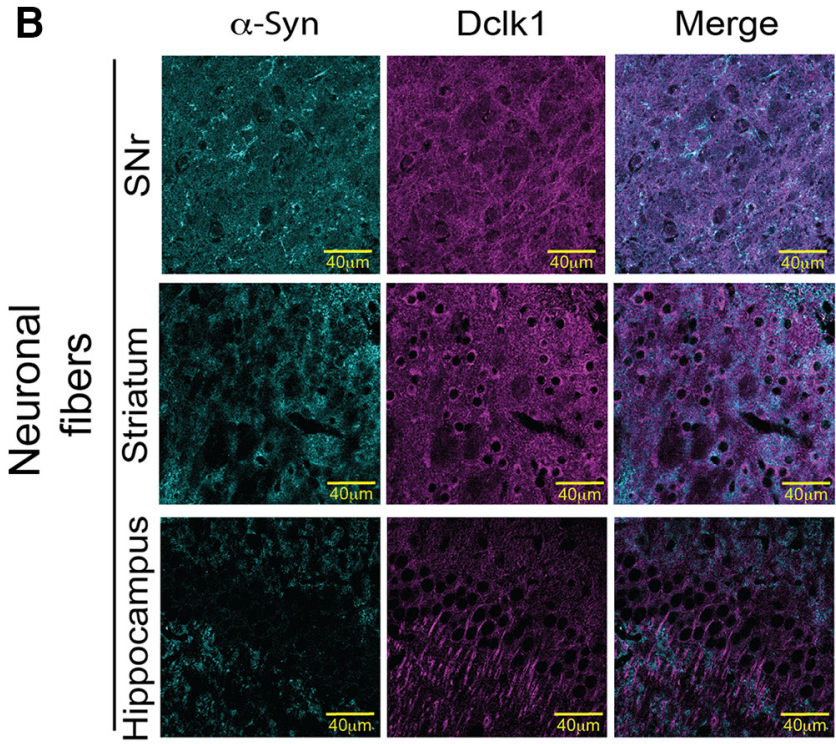

C
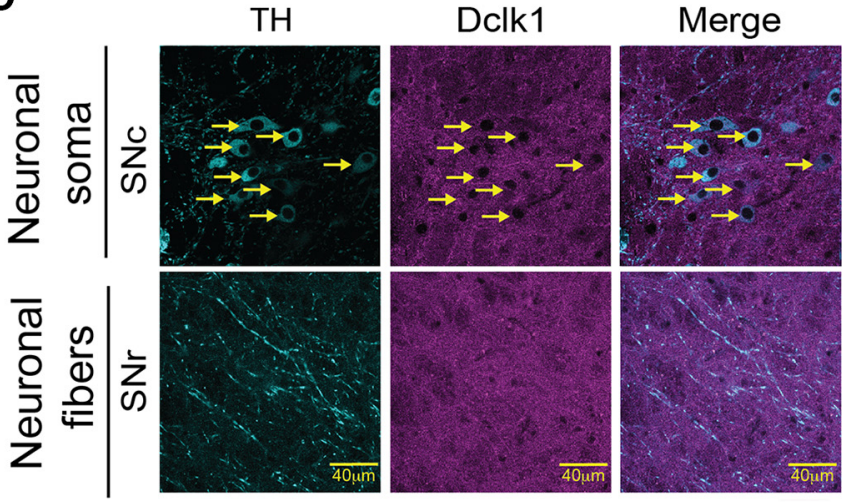

D

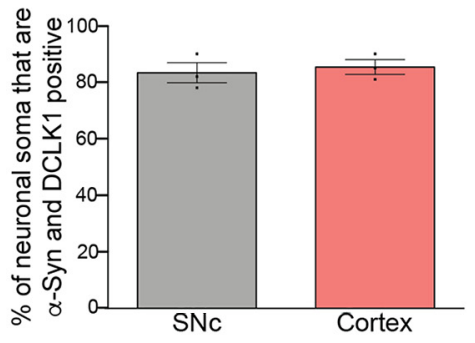

$\mathbf{E}$

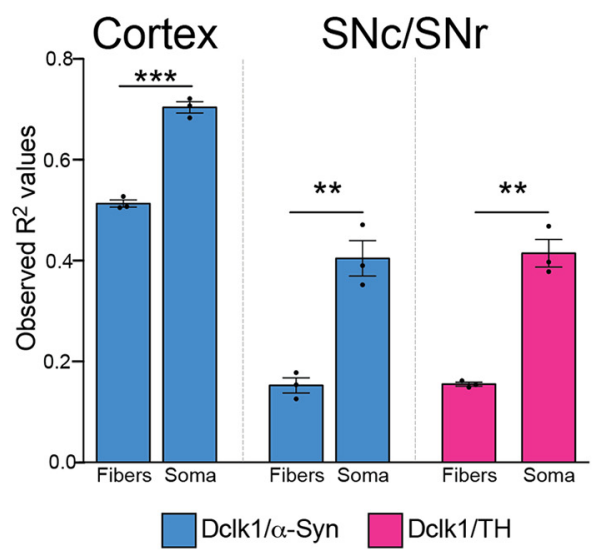

Figure 2. Dclk1 and $\alpha$-Syn are both present in neuronal soma. A, Representative IF images of neuronal soma stained with anti-Dclk1 and anti- $\alpha$-Syn (BD42) in the cortex and SNc. Yellow arrows indicate neuronal soma that express both proteins. $\boldsymbol{B}$, Representative images of IF of anti-Dclk1 and anti- $\alpha$-Syn (BD42)-positive neuronal fibers in the SNr, striatum, and hippocampus. Dclk1-positive fibers appear to be opposed to $\alpha$-Syn-positive fibers in all three regions. C, Representative images of IF using anti-Dclk1 and anti-TH antibodies in the SNc and SNr. Yellow arrows indicate neuronal soma that are positive for TH and Dclk1. TH-positive fibers and Dclk1-positive fibers in the SNr appear to be opposed. D, The proportion of neurons in either the cortex or the SNc that are Dclk1 and $\alpha$-Syn-positive was quantified and is shown as a bar graph. Each data point represents 1 animal. Error bar indicates SEM. E, Colocalization analysis of cortical and nigral sections. The extent of colocalization was quantified as the degree of positional correlation between anti-Dclk1 and anti- $\alpha$-Syn pixels (blue bars) (cortex, $t=14.52, p=0.0001 ; 5 \mathrm{Nc} / \mathrm{SNr}, t=6.593, p=0.0027$ ). The same analysis was done for anti-Ddlk1 and anti-TH staining (light purple bars) $(t=9.380, p=0.0007)$. Error bars indicate SEM. Student's $t$ test: NS $\geq 0.05 ;{ }^{*} p \leq 0.05 ;{ }^{* *} p \leq 0.01 ;{ }^{* * *} p \leq 0.001$; $* * * * 00.0001$.

phosphatase inhibitors and incubated on ice for $20 \mathrm{~min}$. Meanwhile, the beads were washed 3 times in NETT buffer. The protein lysates were then spun down at $13,000 \mathrm{rpm}$ for $20 \mathrm{~min}$ at $4^{\circ} \mathrm{C} ; 50 \mu \mathrm{l}(5 \%)$ of cell lysate were kept for input, and each cell lysate was then added to $10 \mu \mathrm{l}$ of conjugated beads. The samples were then incubated for $30 \mathrm{~min}$ at $4^{\circ} \mathrm{C}$. The beads were washed 5 times in $1 \mathrm{ml}$ of NETT buffer, and the washed samples were eluted in a 1:1 mix of NETT buffer, and $2 \times$ Laemmli sample buffer at $85^{\circ} \mathrm{C}$ for $10 \mathrm{~min}$, spun down for $30 \mathrm{~s}$ at $13,000 \mathrm{rpm}$, and loaded onto an SDS-PAGE gel as described above.

In vitro kinase assay

This assay was performed in a similar way to what was described by Bondar et al. (2018). Full-length human SNCA DNA was cloned into a pDEST15 vector (GST-tagged, Invitrogen,11802014) and transformed into BL21AI (Invitrogen, C607003). GST- $\alpha$-Syn were purified through a GST column. Briefly, $5 \mu \mathrm{g}$ of recombinant $\alpha$-Syn was incubated with 250 ng of active DCLK1 (SignalChem, D14-10G-10) for $1 \mathrm{~h}$ at $30^{\circ} \mathrm{C}$ in kinase buffer (50 mM $\mathrm{PO}_{4}$, pH 7.4, $150 \mathrm{~mm} \mathrm{NaCl}, 20 \mathrm{mM} \mathrm{MgCl}_{2}, 0.1 \mathrm{mg} / \mathrm{ml}$ BSA, $1 \mathrm{~mm}$ DTT) with phosphatase inhibitor (Roche Diagnostics, 04906837001), $20 \mathrm{~mm}$ cold adenosine triphosphate (ATP) (Invitrogen, PV3227) and $1.2 \mathrm{ml}$ of $0.01 \mathrm{mCi} / \mathrm{ml}{ }^{32} \mathrm{P}$ ATP (PerkinElmer, BLU502A250UC). The reactions were terminated by adding sample buffer and boiling the sample at $95^{\circ} \mathrm{C}$ for $10 \mathrm{~min}$. Samples were then run an SDS-PAGE gel as described in SDS-PAGE. The gel was then Coomassie stained (InstantBlue, VWR, 95045-070) for $20 \mathrm{~min}$, and exposed to an X-Ray film (GE Healthcare, 28906845) for $1 \mathrm{~h}$.

\section{Immunofluorescence (IF) and immunohistochemistry}

Tissue preparation. For immunohistochemical experiments, mice were transcardially perfused with PBS followed by $4 \%$ PFA. Brains were dissected and fixed in $4 \%$ PFA for $2 \mathrm{~d}$, dehydrated for $24 \mathrm{~h}$ in $15 \%$ sucrose (w/v, in PBS), followed by a $2 \mathrm{~d}$ incubation in $30 \%$ sucrose solution (in 

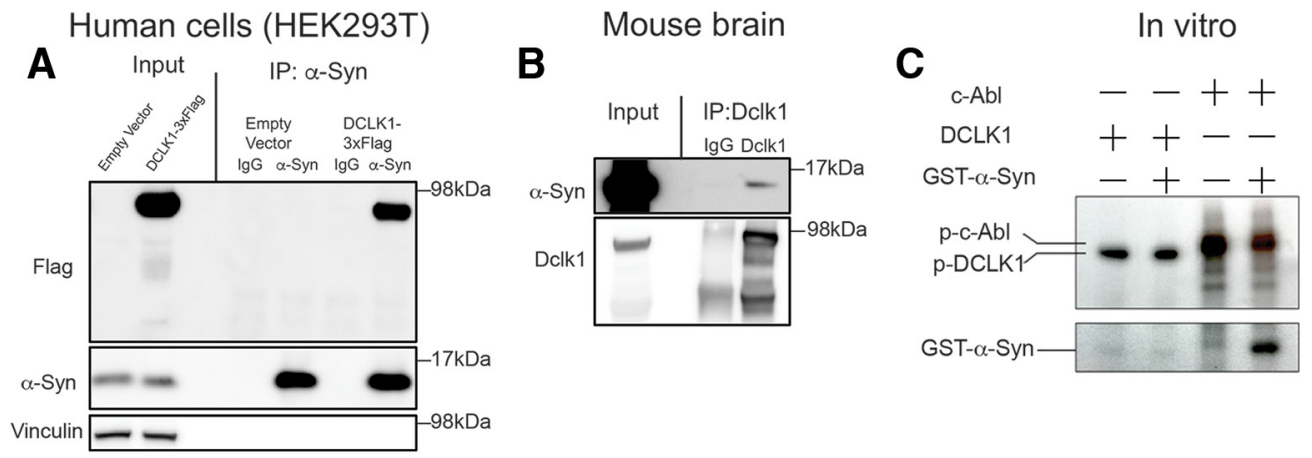

Figure 3. DCLK1 can interact with $\alpha$-Syn but does not phosphorylate it. $A$, Representative blot of co-immunoprecipitation experiments performed in HEK293T cells transfected with either empty vector or DCLK1-3XFlag. Endogenous $\alpha$-Syn was pulled down with anti- $\alpha$-Syn antibody (C-20), and the blots were probed with anti-Flag antibody (M2, Millipore Sigma). $\boldsymbol{B}$, Representative blots of coimmunoprecipitation (Co-IP) experiments from mouse brain using anti-Dclk1 antibodies to pull down endogenous Dclk1 and immunoblotting of $\alpha$-Syn (BD42). C, In vitro kinase assay. Active DCLK1 was incubated with recombinant $\alpha$-Syn. Active c-Abl serves as a positive control. Radioactive ATP was used to detect phosphorylation.

A Full length DCLK1 mRNA

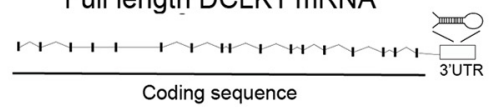

B cDNA (Flag tagged): Full length

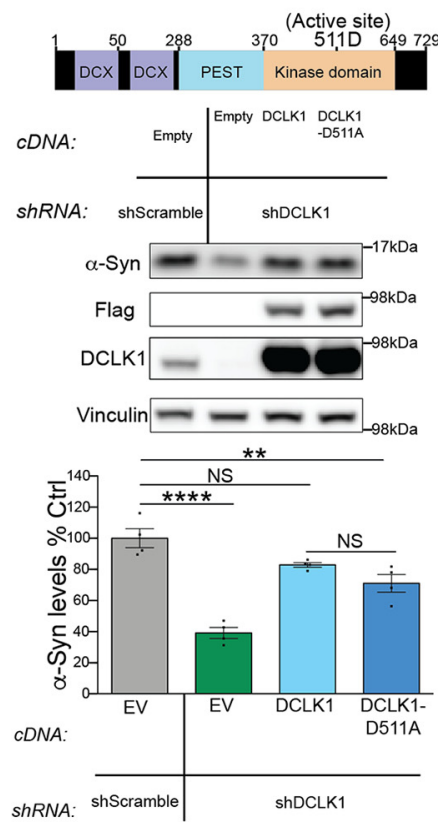

C

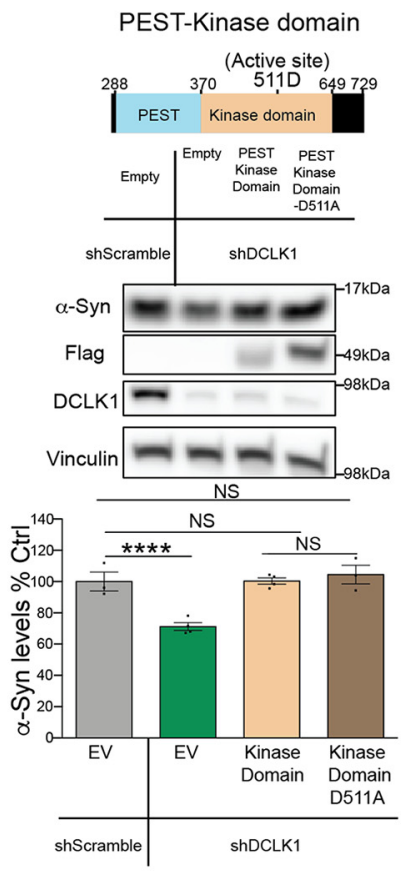

D

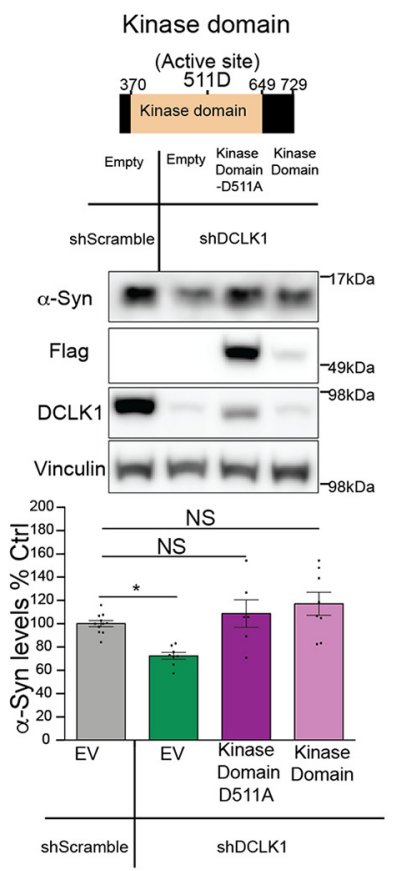

E

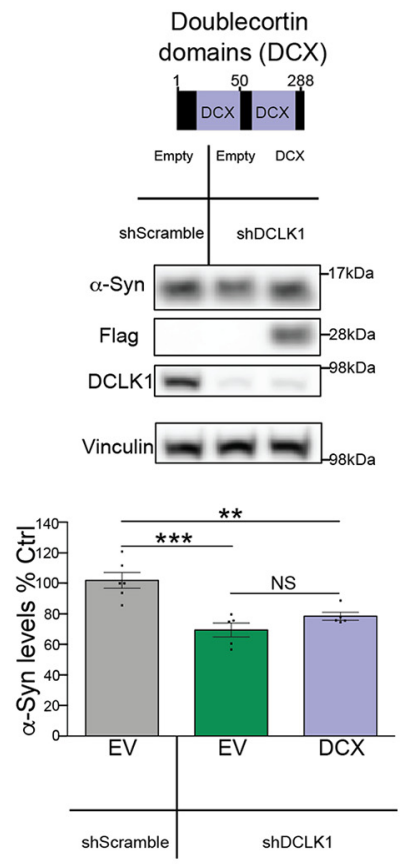

Figure 4. DCLK1 regulates $\alpha$-Syn levels independently of its kinase activity. $\boldsymbol{A}$, Diagram of DCLK1 transcript showing shRNA targeting. $\boldsymbol{B}-\boldsymbol{E}$, DCLK1 Flag tagged constructs were transfected in HEK293T cells after shRNA knockdown of $D C L K 1 . \alpha$-Syn protein levels were measured by Western blot to determine which constructs could rescue the effect of the shRNA. Each data point represents independent sets. $\boldsymbol{B}, F=31.6, p<0.0001 ; \boldsymbol{C}, F=15.97 ; p=0.004 ; \boldsymbol{D}, F=7.877, p=0.005 ; \boldsymbol{E}, F=15.21, p=0.0004$. Error bars indicate SEM. One-way ANOVA, followed by Dunnett's multiple-comparison test: NS $\geq 0.05 ;{ }^{*} p \leq 0.05 ;{ }^{* *} p \leq 0.01 ;{ }^{* * *} p \leq 0.001 ;{ }^{* * * *} p \leq 0.0001$.

$\mathrm{PBS})$, all at $4^{\circ} \mathrm{C}$. The brains were then frozen on dry ice in OCT compound (VWR, 25608-930) and sectioned on a cryostat (Leica Microsystems, CM 3050S). Sections containing the striatum were sectioned at 20 $\mu \mathrm{m}$, and sections containing the SNc were sectioned at $40 \mu \mathrm{m}$. Sections were kept in $1 \times$ PBS with $0.02 \% \mathrm{NaN}_{3}$ until use.

For IF, tissue was drop fixed in 4\% PFA and dehydrated in sucrose solutions in the same way as what was described for IHC sections. All sections for IF were sectioned at $20 \mu \mathrm{m}$.

Staining. Immunohistochemistry was performed as previously described (Rousseaux et al., 2016). Briefly, floating sections were washed 3 times in PBS and then incubated with rabbit anti-TH antibody (EMD Millipore, AB152, RRID:AB_390204), diluted 1/10,000 in PBS supple- mented with $5 \%$ FBS, $0.3 \%$ Triton X-100 overnight at $4^{\circ} \mathrm{C}$. Afterward, the sections were washed 3 more times and stained with the VECTASTAIN Elite ABC HRP Kit (peroxidase, rabbit IgG; Vector Laboratories, PK-6101) according to the manufacturer's instructions. We then used the DAB Peroxidase (HRP) Substrate Kit (with nickel), DAB (Vector Laboratories, SK-4100) to develop the sections. Sections were mounted on Superfrost Plus slides (Thermo Fisher Scientific, 22-037246) and dried at room temperature. Slides were then dehydrated by incubating them in the following series of solutions: $\mathrm{PBS}, \mathrm{H}_{2} \mathrm{O}, 70 \%$ ethanol, $95 \%$ ethanol, $100 \%$ ethanol, and xylene, before mounting coverslips using Richard-Allan Scientific Cytoseal XYL (Thermo Fisher Scientific, 8312-4). 

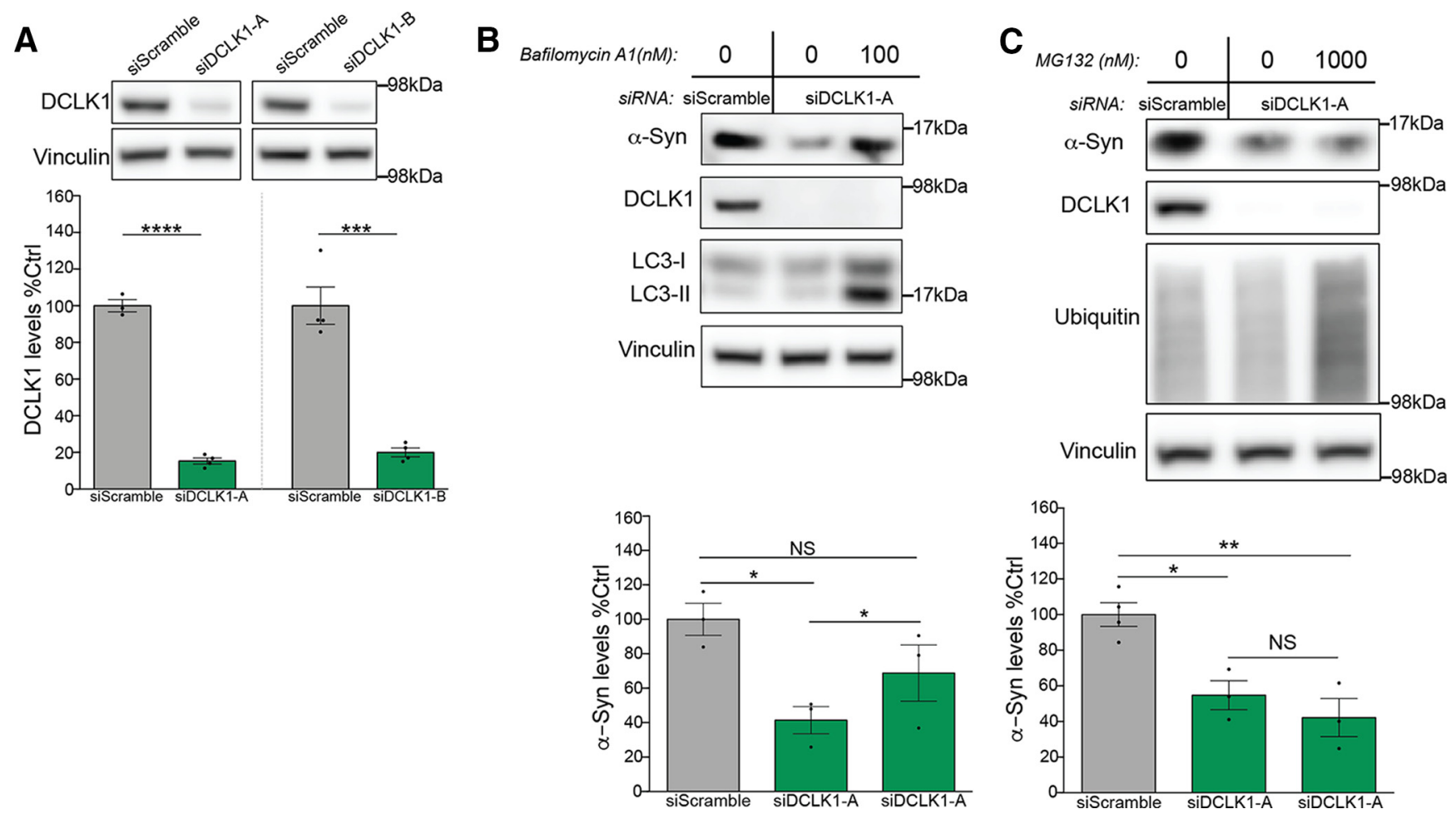

Figure 5. DCLK1 knockdown reduces $\alpha$-Syn levels via lysosomal degradation. $A$, Western blot of HEK293T samples transfected with two DCLK1 siRNAs. siDCLK1-A was selected for further experiments (siDCLK1-A, $t=24.97, p<0.0001 ;$ siDCLK1-B, $t=7.659, p<0.0003$ ). $B, 100 \mathrm{~nm}$ of bafilomycin-A1 was used to inhibit lysosomal activity for $18 \mathrm{~h}$ before cell lysis. $\alpha$-Syn levels (MJFR1) were measured by Western blot $72 \mathrm{~h}$ after siRNA transfection. LC3 immunoblot shows the expected increase in LC3-II after treatment with the drug $(F=6.211, p=0.0345)$. C, 1000 nm of MG132 was used to inhibit proteasomal activity for $12 \mathrm{~h}$ before cell lysis. $\alpha$-Syn levels (MJFR1) were measured by Western blot $72 \mathrm{~h}$ after siRNA transfection. Immunoblot of polyubiquitinated proteins is shown to demonstrate the efficacy of the drug $(F=14.41, p=0.0033)$. Error bars indicate SEM. Student's $t$ test $(\boldsymbol{A})$ and one-way ANOVA, followed by Dunnett's multiple-comparison test $(\boldsymbol{B}, \boldsymbol{C})$ : NS $\geq 0.05 ;{ }^{*} p \leq 0.05 ;{ }^{* *} p \leq 0.01 ;{ }^{* * *} p \leq 0.001 ;{ }^{* * *} p \leq 0.0001$.

IF was performed as previously described (Rousseaux et al., 2016). Briefly, floating sections were washed 3 times in PBS, and then incubated with one or two of the following antibodies: mouse anti- $\alpha$-Syn clone 42 (BD Biosciences, 610787, RRID:AB_398108) 1/500 (recognizes human and mouse $\alpha$-Syn), rat anti-human $\alpha$-Syn 15 G7 (Enzo, ALX-804-258L001, RRID:AB_2050691) 1/250, phospho- $\alpha$-Syn (Ser129) (D1R1R) rabbit mAb (CST, 23706S, RRID:AB_2798868) 1/500, rabbit polyclonal anti-Dclk1 1/500 (Abcam, ab31704), mouse anti-Neurofilament-M (NF-M; RMO, 14.9, 1/1000) (CST, 2838, RRID:AB_561191), mouse anti-synaptophysin (7H12, 1/1000) (CST, 9020, RRID:AB_2631095), or mouse anti-Tyrosine Hydroxylase (anti-TH) 1/10,000 (Immunostar, 22941, RRID:AB_572268) diluted in PBS supplemented with 5\% FBS, $0.3 \%$ Triton $\mathrm{X}-100$ overnight at $4^{\circ} \mathrm{C}$. The next day, sections were washed 3 times in PBS before being incubated with one of the following antibodies diluted in the same solution used for the primary antibody: Invitrogen goat anti-mouse IgG (H+L) AlexaFluor-488 (A-11001, RRID: AB_2534069), goat anti-rabbit IgG (H+L) AlexaFluor-555 (A-21428, RRID:AB_2535849), or goat anti-rat IgG $(\mathrm{H}+\mathrm{L})$, AlexaFluor-555 (A21434, RRID:AB_2535855), goat anti-mouse IgG $(\mathrm{H}+\mathrm{L})$ highly crossadsorbed secondary antibody, AlexaFluor-Plus 555 (A32727, RRID: $\left.A B \_2633276\right)$, and goat anti-mouse IgG $(\mathrm{H}+\mathrm{L})$ highly cross-adsorbed secondary antibody, AlexaFluor Plus-647 (A32728, RRID:AB_2633277). Sections were then washed 3 more times in PBS and mounted using ProLong Gold Antifade Mountant (Invitrogen, P36930).

\section{Human neuron preparation}

IF of human neurons was performed similarly to what was described previously (Jiang et al., 2017). Briefly, human neurons were cultured for 3 weeks. Cells were washed in PBS to remove the media. They were then subjected to a 20 min fixation in 4\% PFA and then washed three times with PBS. Finally, we performed a 10 min permeabilization in $0.1 \%$ Triton-PBS and 30 min blocking with 5\% donkey serum before applying primary antibody. The following primary antibodies were used in human neuron studies: rabbit anti-GABA (Millipore Sigma, A2052-25UL, RRID:AB_477652), mouse anti-VGLUT1 (Millipore Sigma, AMAb91041100UL, RRID:AB_2665777), rabbit anti-MAP2 (EMD Millipore, AB5622, RRID:AB_91939), and mouse anti-tubulin (Beta III) (EMD Millipore, MAB1637, RRID:AB_2210524). All secondary antibodies were used $1 / 1000$. The rest of the procedure is similar to what is described for IF in mouse brain.

\section{Immunofluorescent imaging}

All imaging was performed on a confocal microscope (Leica Microsystems, STED TCS SP8), using LAS X software (Leica Microsystems) to select optimal settings for image capture. All confocal IF images presented in this study were taken with the $63 \times$ objective. All YFP images represent fluorescence coming directly from this protein; no anti-YFP immunostaining was performed. Epifluorescent IF images were taken at $20 \times$.

\section{Immunofluorescent quantification}

All quantifications were performed using Fiji software (Schindelin et al., 2012). Briefly, $Z$ stacks were loaded onto the software. For quantification of $\alpha$-Syn fluorescence in the soma, the experimenter selected the brightest YFP-positive cells (marking the cell as infected with AAV) and quantified the mean fluorescent signal of pS129 $\alpha$-Syn or human $\alpha$-Syn (555 or 568) and NF-M 647 from each YFP-positive soma in the YFP (488) channel as well as the 568 channel (pS129 $\alpha$-Syn or human $\alpha$-Syn). The mean fluorescence values of the fluorophore of interest were normalized to the NF-M signal before comparison. For quantification of $\alpha$-Syn fluorescence outside of the soma, the experimenter quantified the raw integrated density of fluorescence inside and outside cells in an individual plane of a $z$ stack for the previously mentioned $\alpha$-Syn species as well as synaptophysin (647). Then the experimenter subtracted the signal emanating from cells, and normalized the $\alpha$-Syn fluorescence values to those of synaptophysin before comparison between experimental and control 

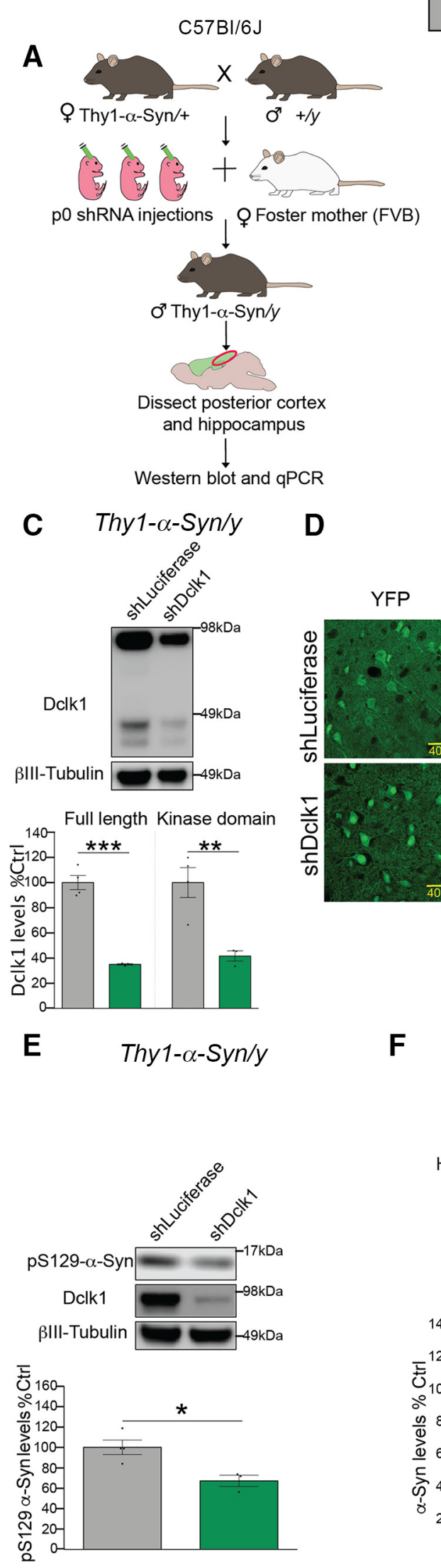
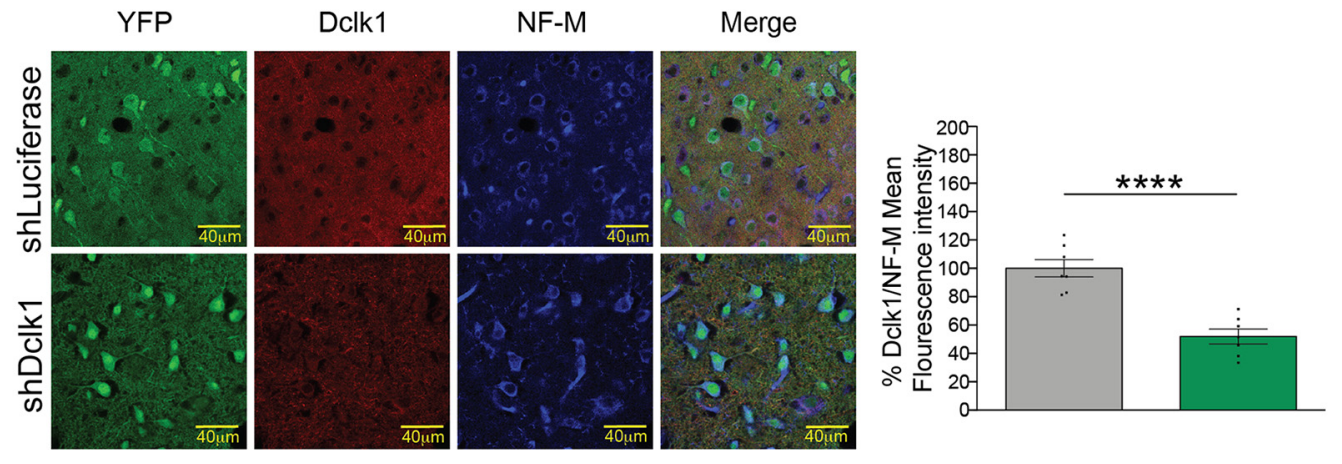

shLuciferase $\square$ shDclk1

B
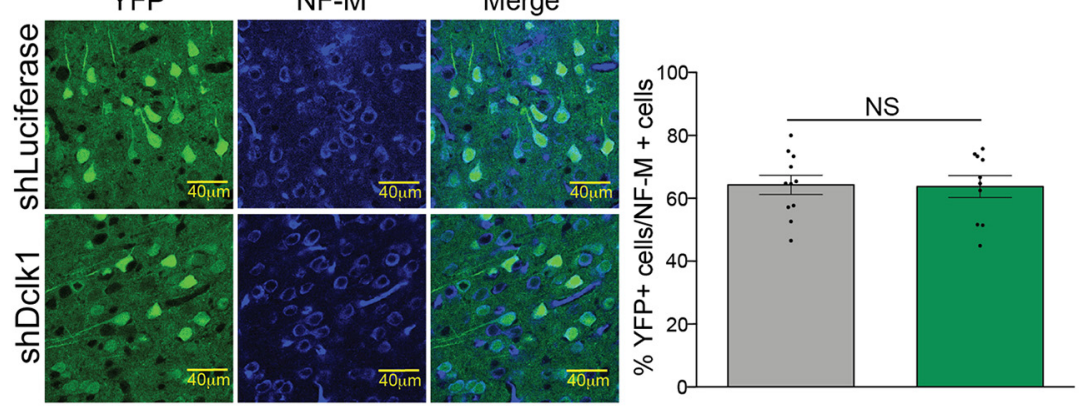

Thy1- $\alpha-S y n / y$

$\mathbf{F}$

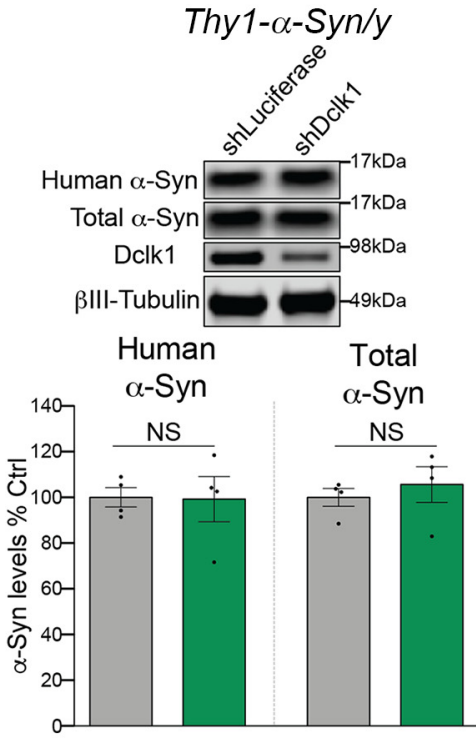

G

Thy1- $\alpha-S y n / y$

Figure 6. Dclk1 knockdown preferentially reduces $\mathrm{pS} 129-\alpha$-Syn in a mouse model of synucleinopathy. A, Diagram of experimental strategy. Thy $1-\alpha$-Syn females were bred to male WT mice. Neonatal intraventricular injections of AAVs carrying shRNA were performed on their pups, and male transgenic mice were killed at 2 months of age. The posterior cortex and hippocampus were dissected and used for all experiments. $\boldsymbol{B}$, Measurement of the proportion of AAV-infected cells in the posterior cortex by IF. The number of YFP cells was divided by the number of NF-M-positive cells in each section $(t=0.1199, p=0.9058)$. C, Western blot measurement of Dclk1 levels from Thy1- $\alpha$-Syn animals after shRNA-mediated Dclk1 (Figure legend continues.) 
conditions. Notably, raw integrated density was selected as this represents the sum of every pixel, and avoids falsely low values attributed to punctate nature of presynaptic protein staining.

To estimate the proportion of cells expressing both $\alpha$-Syn and Dclk1, the experimenter manually counted cells in sections from 3 animals. The number of cells expressing both markers was divided by the total number of visualized cells. To analyze the colocalization between different $\alpha$-Syn species and NF-M, YFP, and synaptophysin, the experiment used the colocalization test function of Fiji software. The observed $R^{2}$ values were then plotted and compared between controls and experimental conditions. The same method was used to calculate the colocalization between Dclk1 and $\alpha$-Syn in the WT mouse cortex and SNc, as well as for Dclk1 and $\mathrm{TH}$ in the SNc.

Stereotaxic injections, stereological counting of dopaminergic neurons, and densitometric measurements of striatal fiber density Stereotaxic injections. Stereotaxic injections were performed as previously described (Rousseaux et al., 2016) with some small modifications to the protocol. Briefly, 2-month-old male C57Bl/6J mice were anesthetized, cleaned with antiseptic, and a midline incision was made to expose the skull. Subsequently, a Hamilton needle containing $2 \mu \mathrm{l}$ of virus was used to deliver virus mixture to the SNc (coordinates from bregma: AP -2.9 , ML 1.3, DV -4.2) at $0.2 \mu \mathrm{l} / \mathrm{s}$ rate over $10 \mathrm{~min}$. The virus mixture included either shLuciferase + SNCA-Flag or shDclk1 + SNCA-Flag $(3 \times$ $10^{9} \mathrm{gc}, 1 \times 10^{9} \mathrm{gc}$ ) (see Production of AAV8 section). After the injection was finished, the needle was removed, and the incision was sutured and glued. Animals were housed for 2 months after injections before being euthanized. All surgeries performed in mice were approved by the Institutional Animal Care and Use Committee for Baylor College of Medicine and Affiliates and in accordance with institutional animal protocols.

Stereological counts of dopaminergic neurons. Stereological counts were performed as previously described (Rousseaux et al., 2016). Briefly, sections from -2.54 to -4 from bregma were selected for staining in intervals of six. IHC for TH was performed as described above. Sections were then coded so that the experimenter was blinded. All IHC for stereology was imaged at $1000 \times$. The representative images were taken using a $20 \times$ objective on a Carl Zeiss AXIO observer microscope equipped with a motorized stage (MBF). Optical fractionation was then used to estimate total dopaminergic cell counts in the SNc of each group (Stereo Investigator, MBF). To conduct this method, the experimenter outlined the ipsilateral (injected) and contralateral (not injected) SNc for each section using the software. Then the software automatically generated random windows that sampled each section, and the experimenter counted $\mathrm{TH}^{+}$ cell bodies. The software then estimated the total number of cells using the measured tissue thickness.

Quantification of striatal TH density. Quantification of striatal TH optical density was performed as previously described (Rousseaux et al., 2016). Briefly, images of the striatum corresponding to the ipsilateral and contralateral sides were captured using the $20 \times$ objective (Carl Zeiss, Axio Scan.Z1). Images were then converted to grayscale using an inhouse automated Adobe Photoshop CS5 workflow (Automator, Mac OSX). Five regions across each striatal section were sampled and normal-

\footnotetext{
$\leftarrow$

(Figure legend continued.) knockdown (full-length, $t=9.706, p=0.0002$; kinase domain, $t=4.042, p=0.0099)$. D , Representative IF images from the cortex of Thy $1-\alpha$-Syn animals for verification of Dclk1 knockdown. Dclk1 mean fluorescence intensity was measured in the soma of neurons and normalized to mean fluorescence intensity of NF-M for quantification ( $t=$ $5.972, p<0.001)$. $\boldsymbol{E}$, Western blots of pS129- $\alpha$-Syn protein levels $(t=3.419, p=0.0189) . \boldsymbol{F}$, Western blots of human $\alpha$-Syn (MJFR1) and total $\alpha$-Syn (BD42) protein levels (human $\alpha$-Syn, $t=0.9493, p=0.3791$; total $\alpha$-Syn, $t=1.347, p=0.2266)$. G, Endogenous Dclk1 immunoprecipitation in the Thy1- $\alpha$-Syn brain followed by immunoblot for $\alpha$-Syn species. pS129- $\alpha$ Syn (D1R1R), human $\alpha$-Syn (MJFR1), and total $\alpha$-Syn (BD42) were detected upon Dclk1 pulldown. All IF images were taken at $63 \times$, and data points represent the individual sections. $n=3$ or 4 per condition. For Western blotting and $q \mathrm{PCR}$, each data point represents individual animals. Error bars indicate SEM. Student's $t$ test: NS $\geq 0.05 ;{ }^{*} p \leq 0.05 ;{ }^{* *} p \leq 0.01 ;{ }^{* * *} p \leq$ $0.001 ; * * * * 0.0001$.
}

ized using the negative staining from the corpus callosum. Normalized values across three sections were used to compare groups.

\section{Cell line culture and transfection}

Cell culture. HEK293T cells (ATCC, CRL-3216) were cultured on DMEM (Corning, MT10013CV) supplemented with 10\% FBS (Atlanta Biological, S11150), and $1 \times$ antibiotic/antimycotic (Invitrogen, 15240062).

Transfection. Transfection experiments for measurement of protein levels were performed in 24-well plates (Corning, CLS3527-100EA). HEK293T cells were seeded at 50,000 cells/well. They were then transfected with $1 \mu \mathrm{g}$ of DNA using MIRUS TransIT-293 reagent (MIR 2706) according to the manufacturer's instructions. For IP transfections, see Immunoprecipitation.

\section{Viral transduction}

HEK293T cells were seeded in 96-well plates (5000 cells/well) and infected with excess of virus ( $10 \mu \mathrm{l}$ of concentrated virus); $24 \mathrm{~h}$ later, cells were selected with puromycin $(1 \mu \mathrm{g} / \mu \mathrm{l})$ for an additional $72 \mathrm{~h}$. The cells were then cultured for at least $10 \mathrm{~d}$ in Complete DMEM before experimental use.

\section{siRNA-mediated knockdown}

Transient knockdown of Dclk1 was accomplished by transfecting Silencer small interference RNA (siRNA) ( $32 \mathrm{~nm}$ ) from Thermo Fisher Scientific (catalog \#AM51331, siRNA IDs: 574, and 575) using $0.5 \mu \mathrm{l}$ of Dharmafect (Dharmacon, T-2001-01) per well in HEK293T cells plated in 24 wells $(50,000$ cells/well). The cells were cultured in antibiotic free media for $72 \mathrm{~h}$ before lysis.

\section{Lysosomal and proteasomal inhibition}

To inhibit the lysosomal function in HEK293T cells, cells were treated $18 \mathrm{~h}$ before lysis with $100 \mathrm{~nm}$ of Bafilomycin A1 (Millipore Sigma, 196000). To inhibit proteasomal function, cells were treated $12 \mathrm{~h}$ before lysis with $1000 \mathrm{~nm}$ of MG132 (Millipore Sigma, 474790). The efficacy of lysosomal inhibition was assessed by Western blotting with rabbit antiLC3 (Novus Biologicals, NB100-2220, RRID:AB_10003146). The efficacy of proteasomal inhibition was determined by immunoblotting for poly-ubiquitinated proteins using mouse anti-ubiquitin (P4D1) antibody (CST, 3936, RRID:AB_331292)

\section{Human neuron culture}

Generation of human neurons by differentiation of induced pluripotent stem cells (iPSCs). The derivation and culture of human neurons for short-hairpin RNA (shRNA) knockdown experiments were performed as described previously (Rousseaux et al., 2018). Briefly, we generated and expanded neuronal progenitors from the ND50042 line (SNCA triplication female patient), and from WA09 (H9) embryonic stem cells (ESCs) (WiCell, WAe009-A). We obtained NN0000049 iPSCs from the National Institute of Neurological Disorders and Stroke Human Cell and Data repository (Patient NDS00201, iPSC line ID: ND50040; RUID = NN0000049). We obtained H9 ESCs from Dr. Jean Kim (Baylor College of Medicine) under agreement with WiCell. NPCs were cultured for at least 1 week after thawing (with media changes every 2-3 d). Accutase was then used to passage the NPCs at a density of 15,000 cells per $\mathrm{cm}^{2}$ in 24-well plates coated with Cultrex (Stem Cell Qualified, Reduced Growth Factor BME, Trevigen, \# 3434-010-02). Three weeks later, the neurons were infected with pGIPZ lentiviruses carrying shRNA (Dharmacon) at an Multiplicity of infection (MOI) of 20. Six days after infection, the neurons were selected with $1 \mathrm{mg} / \mathrm{ml}$ puromycin for 5-6 d. At $14 \mathrm{~d}$ after infection, protein was extracted as described in Protein extraction methods.

Direct conversion of iPSCs into human neurons. SNCA triplication (Patient NDS00201, iPSC line ID: ND34391; RUID = NN0003871) and isogenic control $\left(S N C A^{W T}\right.$ ) iPSCs were generated as previously described (Heman-Ackah et al., 2017). To confirm successful differentiation of each line, a modified version of the direct differentiation protocol described previously by others was used (Thoma et al., 2012; Zhang et al., 2013; Ho et al., 2016). Briefly, $2 \times 10^{6}$ iPSCs suspended as single cells in mTeSR1 basal media (Stem Cell Technologies, 85850 ) with $10 \mu \mathrm{M}$ of Y-27632 (Tocris Bioscience, TB1254-GMP) were 


\section{Thy1- $\alpha-S y n / y$}

A

Neuronal fibers
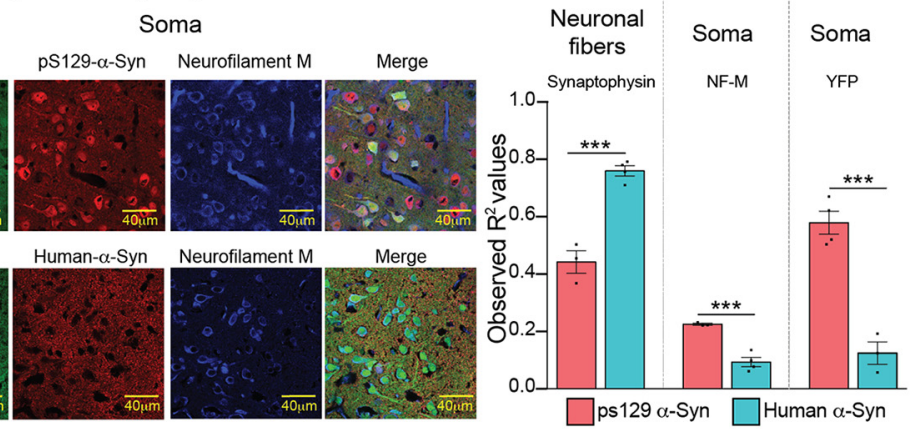

B

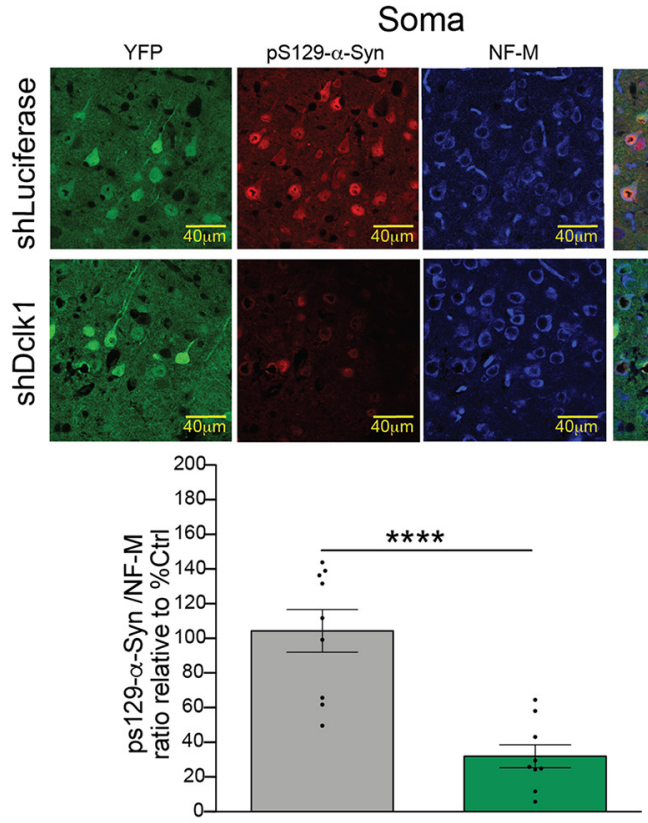

D
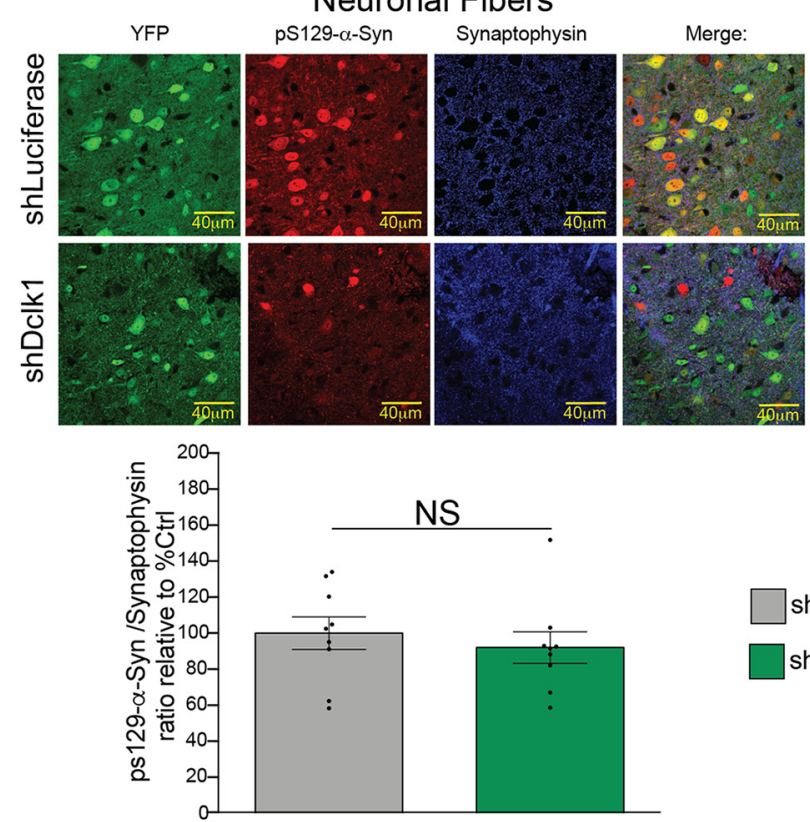

C

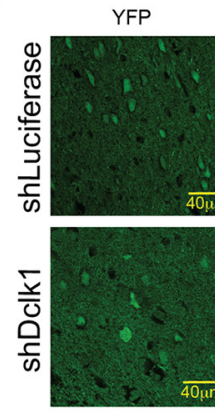

Soma

Human- $\alpha$-Syn
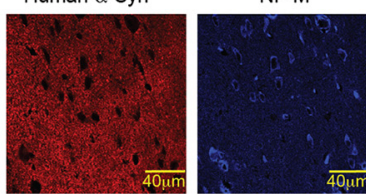

Merge:
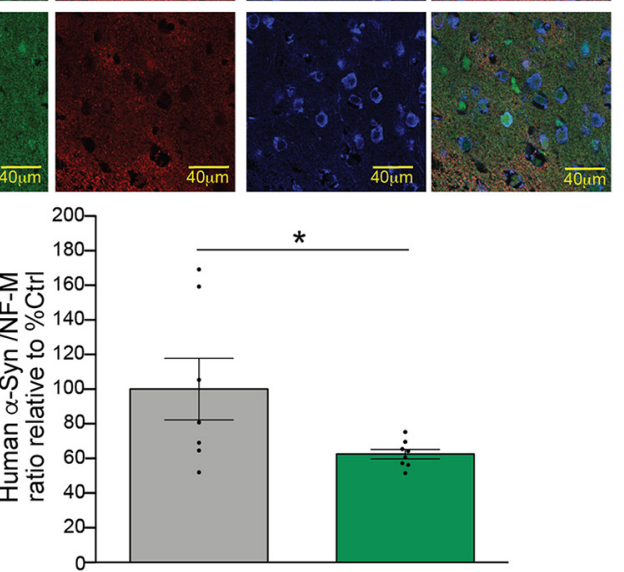

E
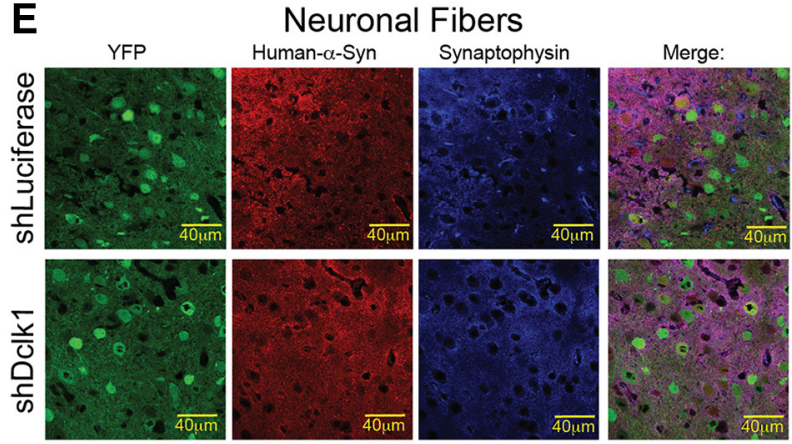

NS

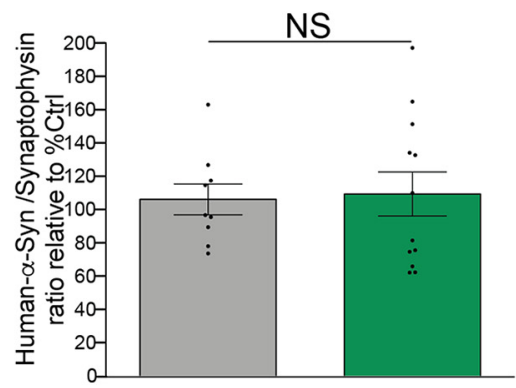

Figure 7. Knockdown of DCLK1 preferentially affects $\alpha$-Syn species in the soma of Thy1- $\alpha$-Syn mouse cortex. A, Colocalization analysis of pS129- $\alpha$-Syn (D1R1R), and overexpressed human $\alpha$-Syn (15G7) with markers for neuronal fibers (synaptophysin) and neuronal soma (neurofilament-M and YFP) (neuronal fibers, $t=8.067, p=0.0005 ;$ soma NF-M, $t=6.881, p=0.001 ;$ soma YFP, $t=7.906, p=0.0005$ ). $B$, Representative images (top) and quantification (bottom) of mean fluorescence intensity of pS129- $\alpha$-Syn in neuronal soma relative to NF-M ( $t=5.181, p<0.0001$ ). C, Representative images (top) and quantification (bottom) of mean fluorescence intensity of human- $\alpha$-Syn in neuronal soma relative to NF-M $(t=2.239, p=0.0433)$. $\boldsymbol{D}$, Representative images and quantification of raw integrated fluorescence intensity of pS129- $\alpha$-Syn in neuronal fibers normalized to synaptophysin. The fluorescence from cell bodies (Figure legend continues.) 
infected with a modified version of hNGN2-eGFP-Puro plasmid (RRID: Addgene_79823). In this plasmid, which was a gift from Dr. Kristen Brennand (Ho et al., 2016), the puromycin selection cassette was replaced with blasticidin selection, and the GFP fluorescent marker was replaced with mCherry (hNGN2-mCherry-Blast) (Crutcher et al., 2019). The iPSCs were incubated in suspension overnight and moved to Matrigel (Corning, 477343-706)-coated plates on the following day. After several days of expansion and passaging with Accutase (A6964, Millipore Sigma), the iPSCs were plated $\left(0.125 \times 10^{6} \mathrm{cells} / \mathrm{cm}^{2}\right)$ in 12 -well tissue culture plates coated Cultrex (Stem Cell Qualified, Reduced Growth Factor BME, Trevigen, \#3434-010-02). They were then induced using neuronal induction media (NIM-DMEM/F-12:Neurobasal (1:1) with $1 \times$ penicillin-streptomycin, 2\% B-27 without vitamin A, 1\% N-2, $2 \mathrm{~mm}$ Glutamax, all from Thermo Fisher Scientific, catalog \#A1647801, $21103049,10378016,12587010,17502001$, and 35050061, respectively) supplemented with doxycycline $(2 \mu \mathrm{g} / \mathrm{ml})$ (Stem Cell Technologies, 72742), and SMAD inhibitors, $1 \mu \mathrm{M}$ dorsomorphin (sc-361173, Santa Cruz Biotechnology) and $10 \mu \mathrm{M}$ SB431542 (S1067, Selleck Chemicals). Two days later, the media was changed to neural differentiation media (NDM-Neurobasal medium with $1 \times$ penicillin-streptomycin, 2\% B-27 without vitamin A, 2 mm Glutamax) supplemented with $20 \mathrm{ng} / \mathrm{ml} \mathrm{BDNF}$, $10 \mathrm{ng} / \mathrm{ml} \mathrm{GDNF}$, and $10 \mathrm{ng} / \mathrm{ml} \mathrm{NT-3} \mathrm{(all} \mathrm{three} \mathrm{were} \mathrm{human} \mathrm{animal} \mathrm{free}$ peptides from PeproTech, AF-450-02, AF-450-10, and AF-450-03, respectively), $100 \mu \mathrm{M}$ db-cAMP (sc-201567B, Santa Cruz Biotechnology), and $200 \mu \mathrm{M}$ ascorbic acid (A8960, Millipore Sigma) supplemented with doxycycline, and $20 \mu \mathrm{g} / \mathrm{ml}$ of blasticidin (ant-bl-05, Invivogen) for selection. Blasticidin selection was performed for $6 \mathrm{~d}$ (from day 2 to day 8 ). The cultures were supplemented with $1 \mu \mathrm{g} / \mathrm{ml}$ laminin (3400-010-02, Travigen) once every $4 \mathrm{~d}$ and with Matrigel once every $8 \mathrm{~d}$ to prevent detachment. The cells were kept in culture for a total of $30 \mathrm{~d}$. At the end of this period, protein was extracted as described in the protein extraction section of these methods.

\section{Production of vectors for transfection experiments}

To express different functional domains of DCLK1 in HEK293T cells, we produced a series of new vectors. All of these vectors are based on a modified pcDNA3 that is compatible with Gateway cloning and encodes a 3' 3X-Flag tag (Klisch et al., 2017). We obtained human DCLK1 cDNA (RC217050, OriGene) and PCR amplified the full-length DCLK1 (12188 bp), PEST-kinase domain (862-1941 bp), and doublecortin domains (169-807 bp) from the original vector. We then used the Gateway BP Clonase II Enzyme mix (11789020, Thermo Fisher Scientific) to transfer these sequences onto the Gateway pDONR221 Vector (12536017, Thermo Fisher Scientific). Finally, each insert was transferred unto our customized pcDNA3-3X-Flag vector using Gateway LR Clonase II Enzyme mix (11791020, Thermo Fisher Scientific). All cloning reactions were performed according to the manufacturer's instructions.

To generate kinase dead forms of full-length, and PEST-kinase domain constructs, we used QuikChange II XL Site-Directed Mutagenesis Kit (200521, Agilent Technologies) to perform an alanine substitution on the catalytic domain of DCLK1 (D511A) (Patel et al., 2016) according to the manufacturer's instructions. To generate kinase domain constructs that lack the PEST sequence $(862-1020 \mathrm{bp})$, we also used site-directed mutagenesis to eliminate this sequence from our PEST-kinase domain constructs.

\section{Production and titering of lentiviruses}

Production. Lentiviruses were made according to what was described previously (Rousseaux et al., 2018). HEK293T cells were seeded so that

\footnotetext{
(Figure legend continued.) $\quad$ was subtracted before analysis $(t=0.637, p=0.5331) . \boldsymbol{E}$, Representative images and quantification of raw integrated fluorescence intensity of human- $\alpha$ Syn in neuronal fibers normalized to synaptophysin. The fluorescence from cell bodies was subtracted before analysis $(t=0.1854, p=0.8549)$. All IF images were taken at $63 \times$. Three or four animals were used per condition. Data points represent the individual sections ( 3 sections per animal). Error bars indicate SEM. Student's $t$ test: NS $\geq 0.05 ;{ }^{*} p \leq 0.05 ;{ }^{* * *} p \leq 0.001$; ${ }^{* * * *} p \leq 0.0001$. For images of negative controls please refer to Figure $7-1$ available at $h t t p s: / /$ doi.org/10.1523/JNEUROSCl.1076-19.2019.f7-1.
}

they were $90 \%$ confluency on the day of transfection in $150 \mathrm{~mm}$ dishes. They were transfected using MIRUS-TRANS-IT 293 reagent with pGIPz, psPAX2, and pMD2.G (at a 4:3:1 ratio, $45 \mu \mathrm{g}$ total for $150 \mathrm{~mm}$ dish). Media were collected 48 and $72 \mathrm{~h}$ later, spun down for $10 \mathrm{~min}$ at 4000 $\mathrm{rpm}$ at $4^{\circ} \mathrm{C}$. The viral media were then filtered using $45 \mu \mathrm{m}$ PES filters to remove cellular debris before being concentrated $100 \times$ overnight using Lenti-X concentrator (Clontech, 631231), according to the manufacturer's instructions.

Titering. Titering was performed as previously described (Rousseaux et al., 2018). Briefly, HEK293T cells were seeded at 50,000 cells/well in a 24-well plate. The next day, a serial dilution of the virus was made and cells were infected with each dilution. After $4 \mathrm{~d}$ of culture, GFP-positive colonies were counted and the viral titers were estimated.

\section{Mouse breeding and $p 0$ intraventricular injections}

Swiss Webster (CFW) of both sexes (Charles River, 024), C57Bl/6J (The Jackson Laboratory), and male Thy1- $\alpha$-Syn ("Line 61") (Rockenstein et al., 2002) mice were used for $\mathrm{p} 0$ intraventricular injections. We will refer to these mice as Thy1- $\alpha$-Syn here after. We had previously obtained the Thy1- $\alpha$-Syn and had backcrossed into the C57Bl/6J background (Rousseaux et al., 2016). In all experiments, mice were allowed to breed for $3 \mathrm{~d}$ before the male was removed. In the case of experiments using C57Bl/6] mice, FVB foster mothers were used to house the pups after manipulation to avoid maternal cannibalization. In experiments using the Thy1$\alpha$-Syn, transgenic females were bred to wild type (WT) males. Because the transgene is on the $\mathrm{X}$ chromosome, only the male offspring can be used as females have a larger degree of variability because of $\mathrm{X}$-inactivation. In the case of WT CFW mice, a foster mother was not necessary, and the mice were kept with their mothers after injections. Both sexes were used in this case. All procedures performed in mice were approved by the Institutional Animal Care and Use Committee for Baylor College of Medicine and Affiliates.

\section{Production of Adeno-associated viruses}

We used previously generated AAV8 vectors containing either an shRNA against Luciferase (negative control) or against Dclk1 (Rousseaux et al., 2018). Viruses were produced in collaboration with the Baylor College of Medicine Viral Vector core.

\section{PO AAV injections}

Injections were performed as previously described (Kim et al., 2013; Rousseaux et al., 2018). Briefly, shRNA sequences were obtained using the SplashRNA algorithm and cloned into YFP and miR-E containing AAV8 vectors (Fellmann et al., 2013; Pelossof et al., 2017).

\section{Statistical analyses}

For all experiments, comparisons of two groups were performed using Student's $t$ test, and comparisons of three or more groups were performed using one-way ANOVA followed by Dunnett's multiplecomparison test. All analyses were conducted using Prism 6 software (GraphPad). All error bars represent the standard error of the mean (SEM).

\section{Results}

\section{Dclk1 regulates $\alpha$-Syn levels post-transcriptionally}

We previously used AAV8-mediated intraventricular delivery of shRNAs to knock down Dclk1 in the postnatal brain (posterior cortex and hippocampus) (Fig. 1A) and found that this reduces $\alpha$-Syn protein ( Rousseaux et al., 2018) (Fig. 1B). We used the posterior cortex and hippocampus for these experiments because this region has the highest infection rate using this method (Kim et al., 2013). We hypothesized that Dclk1 regulates the levels of $\alpha$-Syn post-transcriptionally because the two screens that identified $D C L K 1$ were performed on transgenic cell lines that lack the regulatory elements that control SNCA transcription (Rousseaux et al., 2016, 2018). To test this, we performed qPCR to detect the relative abundance of $S n c a$ transcript after $D c l k 1$ knockdown. We did not find any significant difference in Snca transcript after Dclkl knockdown in the mouse brain (Fig. 1B), confirming that 
A

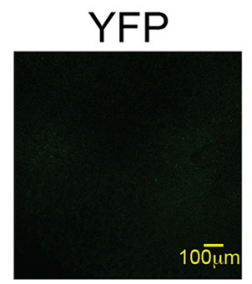

B

Contralateral SNc: Uninjected

Ipsilateral SNc:

AAV-shDclk1+ AAV-Empty Vector

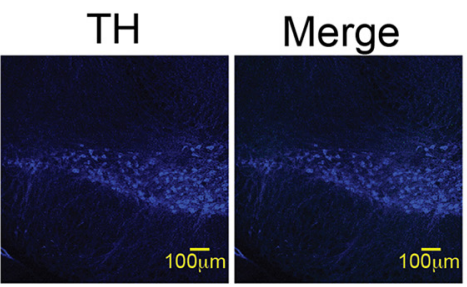

Ipsilateral SNc:

AAV-shDclk1+ AAV-Empty Vector

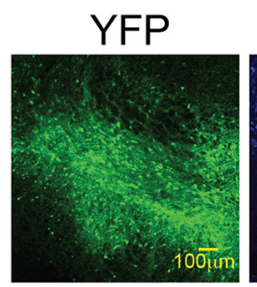

$\mathrm{TH}$
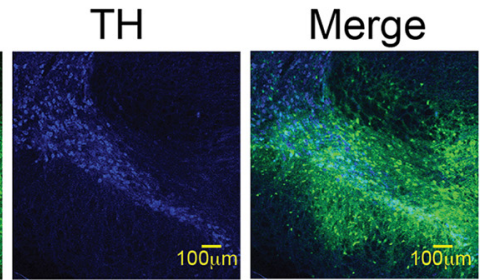

C
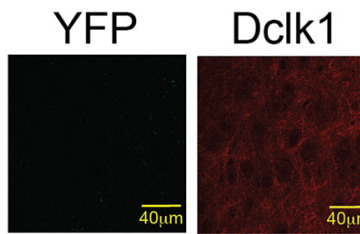

\section{TH}

Merge
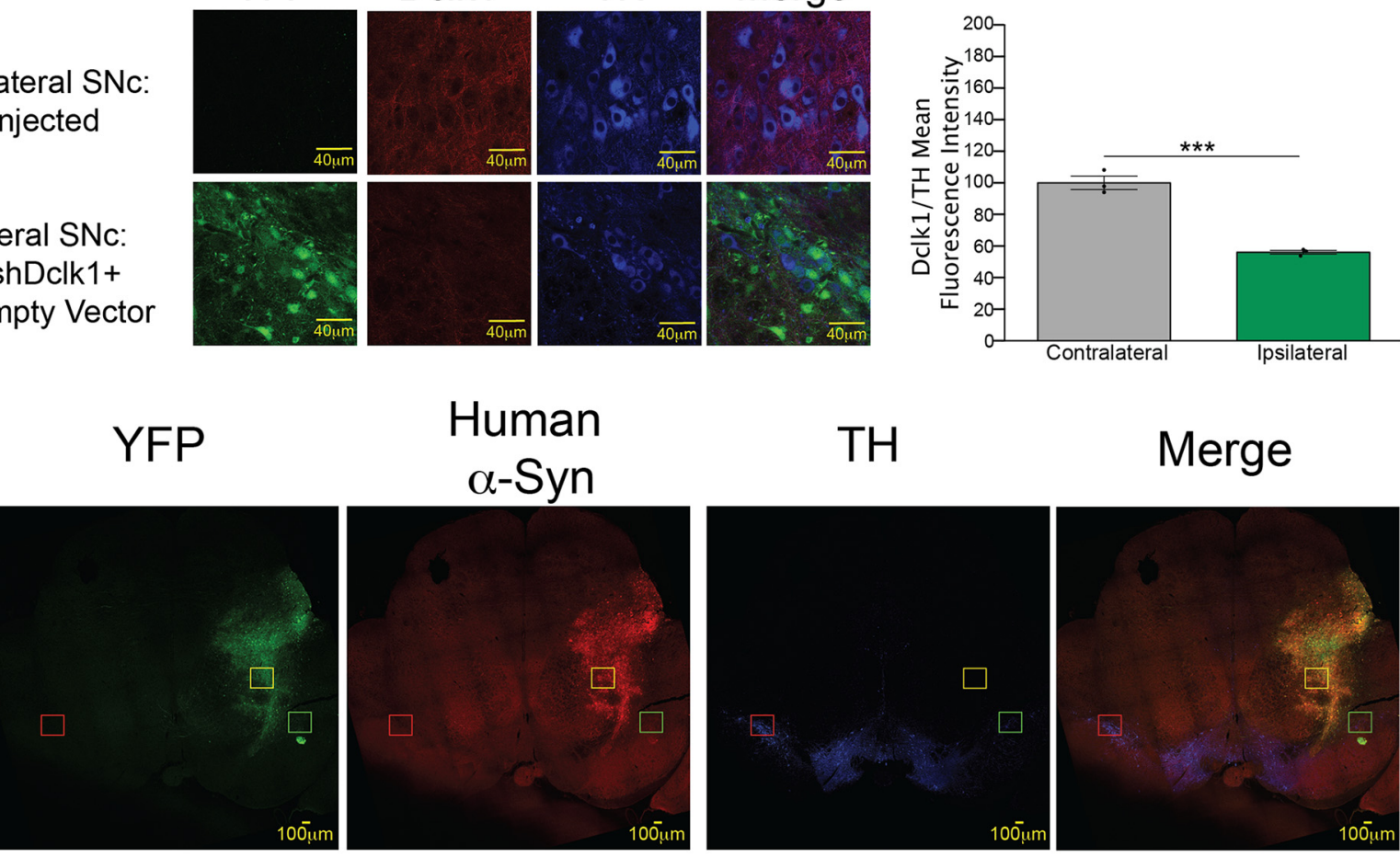

Merge

AAV-SNCA

D

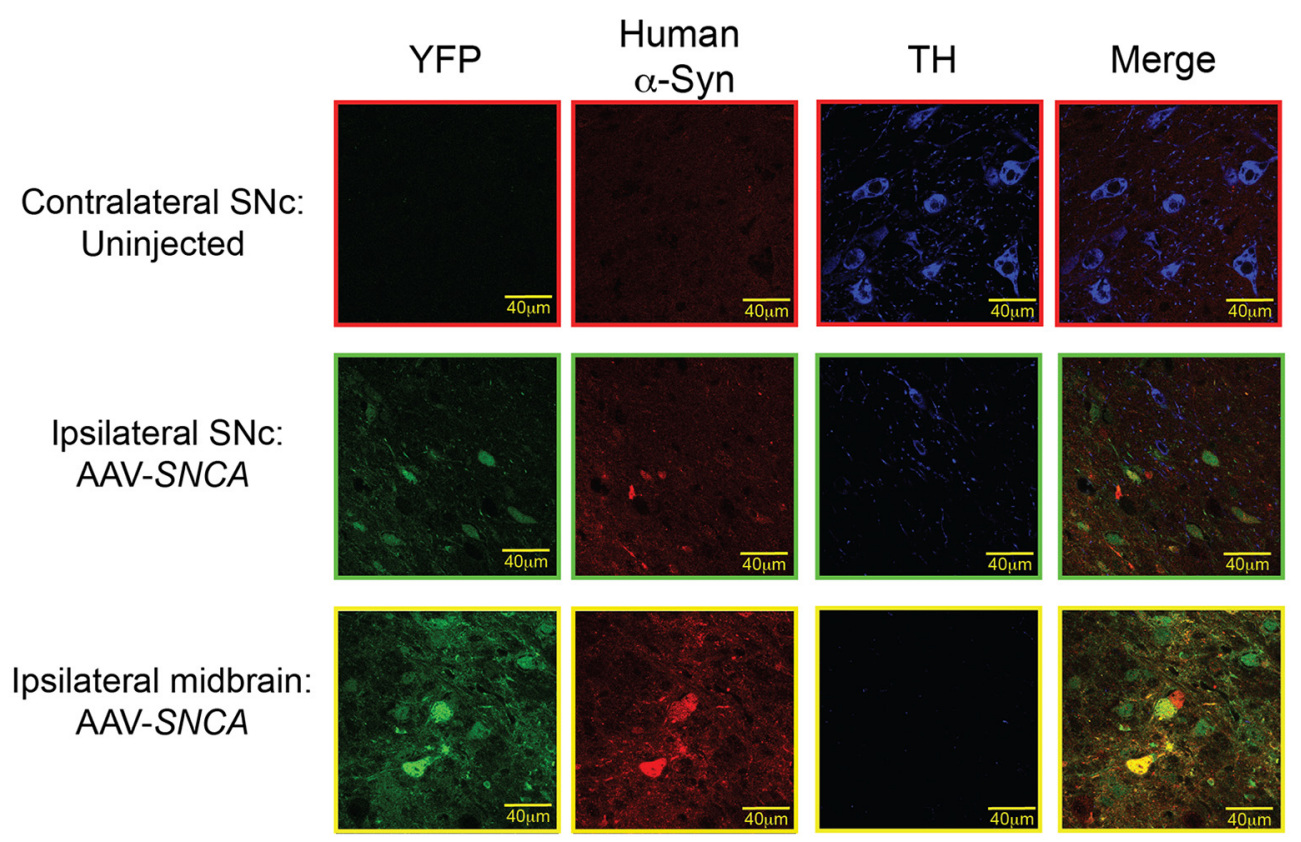

Figure 8. Stereotaxic injection of shDclk1 AAVs was used to knock down Dclk1 and overexpress human $\alpha$-Syn in the SNc of adult mice. $\boldsymbol{A}$, Representative $20 \times$ IF images showing proper targeting of the SNc. Infected dopaminergic neurons are labeled with anti-TH antibody and YFP from the virus. B, Measurement of Dclk1 knockdown in the SNc. Dclk1 mean fluorescence intensity was normalized to TH signal in sections of animals infected with either shLuciferase or shDclk1. Student's $t$ test: ${ }^{* * *} p \leq 0.001(t=10.03, p=0.0006)$. Images are $63 \times$. (Figure legend continues.) 
Dclk1 regulates $\alpha$-Syn protein levels post-transcriptionally. To test whether this modulatory effect is specific to $\alpha$-Syn, we measured the levels of two other neurodegenerative disease-driving proteins: tau and App. In both cases, Dclk1 knockdown did not alter their protein levels (Fig. 1C). The Dclk1 gene has multiple transcripts that include alternative start sites (Burgess and Reiner, 2002; Deuel et al., 2006; Koizumi et al., 2006). In the adult brain, these transcripts code for either the full-length protein or a shortened form that does not include the DCX domains, herein referred to as the "kinase domain" (Fig. 1D). To determine which forms of Dclk1 are affected by our shRNA, we measured the transcript and protein levels. We found that our shRNA could knock down both the full-length $D c l k 1$ as well as the kinase domain transcripts (Fig. 1E).

\section{The Dclk1 kinase domain, but not its catalytic activity, is required for regulation $\alpha$-Syn levels}

To gain insight into the mechanism by which Dclk1 regulates $\alpha$-Syn levels, we first asked whether these two proteins reside in similar neuronal compartments. To answer this question, we labeled sections of mouse cortex and $\mathrm{SNc}$ with anti-Dclk1 and anti- $\alpha$-Syn antibodies to visualize neuronal soma (Fig. $2 A$ ). We also labeled the substantia nigra pars reticulata $(\mathrm{SNr})$, striatum, and hippocampus to visualize neuronal fibers (dendrites and presynaptic terminals) (Fig. 2B). Finally, we also stained nigral sections with anti-TH antibodies and anti-Dclk1 antibodies to determine directly whether dopaminergic neurons express Dclk1 (Fig. $2 C$ ). We found that the majority of neurons $(\sim 80 \%)$ in the cortex and the SNc express both $\alpha$-Syn and Dclk1 (Fig. 2A,D). Moreover, the colocalization of $\alpha$-Syn and Dclk1 was significantly higher in the soma of cortical neurons than in their corresponding fibers (average fiber $R^{2}=0.513$ vs average soma $R^{2}=$ 0.701 ). The difference was also found in the SNc (average $\mathrm{SNr}$ fiber $R^{2}=0.152$ vs average SNc soma $R^{2}=0.403$ ) (Fig. $2 A, B, E$ ). It should be noted that the $R^{2}$ values vary greatly between brain regions, which is possibly due to differences in tissue architecture. Notably, Dclk1 and $\alpha$-Syn fibers in other regions (striatum, hippocampus) were visibly opposed with little overlap. This pattern of colocalization is not surprising given that, outside of the soma, Dclk1 has been reported to be localized to the dendritic compartment (Shin et al., 2013), and $\alpha$-Syn has been reported to be localized to the presynaptic compartment (Withers et al., 1997; Kahle et al., 2000; Unni et al., 2010; Burré et al., 2018). Additionally, Dclk1 staining colocalized more strongly with $\mathrm{TH}$ staining in dopaminergic neuronal soma $(\mathrm{SNc})$ than in their fibers $(\mathrm{SNr})$ (Fig. 2C,E).

Given that the two proteins exist in the same subcellular location, we next asked whether they could interact. We performed IP of endogenous $\alpha$-Syn in HEK293T cells transfected with either empty vector or Flag tagged DCLK1 and found that overexpressed DCLK1 immunoprecipitates with endogenous $\alpha$-Syn in cells. (Fig. 3A). Next, we tested whether this interaction could be detected in vivo. To do so, we immunoprecipitated endogenous Dclk1 and probed for endogenous $\alpha$-Syn in the brains of WT mice. We found that $\alpha$-Syn could be detected at long exposures

\section{$\leftarrow$}

(Figure legend continued.) C, Representative 20X scans of ipsilateral (injected) and contralateral (uninjected) midbrain after AAV-SNCA injection. The needle tract (yellow box) shows human $\alpha$-Syn expression (15G7) in YFP-positive cells. There is a clear reduction in TH-positive cells in the injected SNc (green box) compared with the contralateral SNc (red box). D, 63× IF images from the areas described in C. Error bars indicate SEM.
(Fig. $3 B$ ). It is worth noting that, while we did detect an endogenous interaction between $\alpha$-Syn and Dclk1, the amount of endogenous $\alpha$-Syn that interacted with Dclk1 was very small. These data suggest that the two proteins may interact.

Since Dclk 1 and $\alpha$-Syn can interact (albeit weakly) and coexist in the soma of neurons, and Dclk1 is a protein kinase, we next asked whether DCLK1 can directly phosphorylate $\alpha$-Syn. To test this, we performed an in vitro kinase assay. We found that active DCLK1 is capable of autophosphorylation, but it does not phosphorylate recombinant GST- $\alpha$-Syn. In contrast, c-Abl, a known $\alpha$-Syn kinase (Mahul-Mellier et al., 2014; Brahmachari et al., 2016) phosphorylates $\alpha$-Syn (Fig. 3C). This result suggests that Dclk1 may not directly phosphorylate $\alpha$-Syn. This is perhaps not surprising as $\alpha$-Syn lacks the proposed consensus motif for Dclk1 (R-R-X-X-S*/T*) (Shang et al., 2003; Koizumi et al., 2017).

We next determined whether the kinase activity of DCLK1 is required for its effect on $\alpha$-Syn levels. To answer this question, we performed shRNA-mediated knockdown of endogenous DCLK1 in HEK293T cells and tested whether overexpression of shRNAresistant Flag-tagged constructs containing WT DCLK1 or catalytically dead (DCLK1-D511A) (Fig. 4A) could rescue the effect on $\alpha$-Syn levels. We found that both forms of DCLK1 were able to rescue the decrease in $\alpha$-Syn levels seen upon DCLK1 knockdown (Fig. 4B). Additionally, both WT and catalytically dead kinase domain had the same effect on $\alpha$-Syn levels, regardless of the presence or absence of the PEST sequence (Fig. 4C,D). Conversely, the DCX domains alone failed to change $\alpha$-Syn levels (Fig. 4E). Together, these data suggest that DCLK1 regulates $\alpha$-Syn levels via its kinase domain, but that this effect is not dependent on its kinase activity.

\section{Knockdown of DCLK1 reduces $\alpha$-Syn levels via lysosomal degradation in cells}

To elucidate how the binding of DCLK1 affects $\alpha$-Syn protein levels, we asked whether DCLK1 protects $\alpha$-Syn protein from lysosomal or proteasomal degradation. To test this, we transiently knocked down DCLK1 in HEK293T cells with siRNAs and added either inhibitors of lysosomal function (Bafilomycin A1) or proteasomal function (MG132; Fig. $5 A-C$ ). We found that only exposure to Bafilomycin A1 selectively mitigated the effect of siDCLK1 on $\alpha$-Syn protein levels (Fig. 5B), whereas proteasomal inhibition had no effect (Fig. 5C). This is consistent with reports indicating that the primary mode of $\alpha$-Syn degradation is lysosomal (Cuervo et al., 2004; Lee et al., 2004; Vogiatzi et al., 2008; Tofaris et al., 2011; Oueslati et al., 2013).

\section{Dclk1 knockdown preferentially affects the levels of pS129- $\alpha$ - Syn in transgenic mice and ameliorates toxicity in an AAV- mediated mouse model}

After initially focusing on the mechanism of regulation of endogenous $\alpha$-Syn by Dclk1 in the WT context, we next tested whether this translates to the context of disease, in which pathogenic species $\alpha$-Syn are increased and drive toxicity. To capture the full spectrum of synucleinopathy phenotypes, we used two models to test whether Dclk1 inhibition would prove beneficial. First, to test the effect on the levels of pS129- $\alpha$-Syn, we used the Thy1- $\alpha$-Syn "Line 61" (Rockenstein et al., 2002) mouse model of PD, henceforth referred to as Thy1- $\alpha$-Syn. This line overexpresses WT human SNCA at 10-fold normal levels throughout the brain (Rockenstein et al., 2002; Chesselet et al., 2012). Importantly, pS129 $\alpha$-Syn is thought to be associated with pathology in humans because it is drastically elevated in the brains of PD patients and in Lewy bodies (Fujiwara et al., 2002; Anderson et al., 2006). 
A
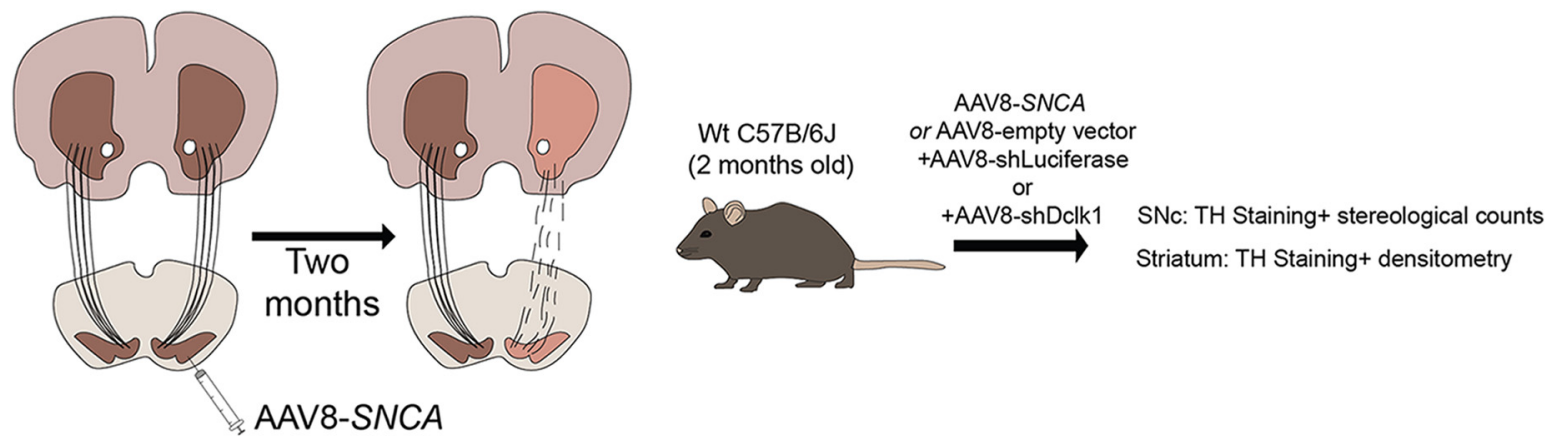

B

\section{Site Contralateral: shRNA uninjected}

C

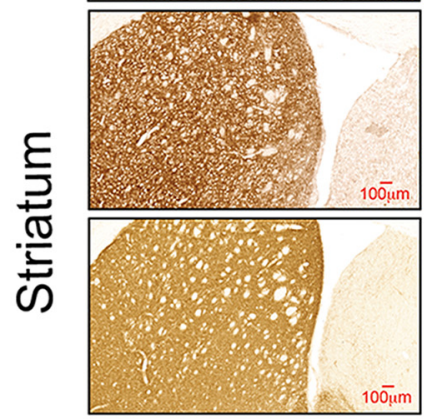

Ipsilateral: shLuciferase
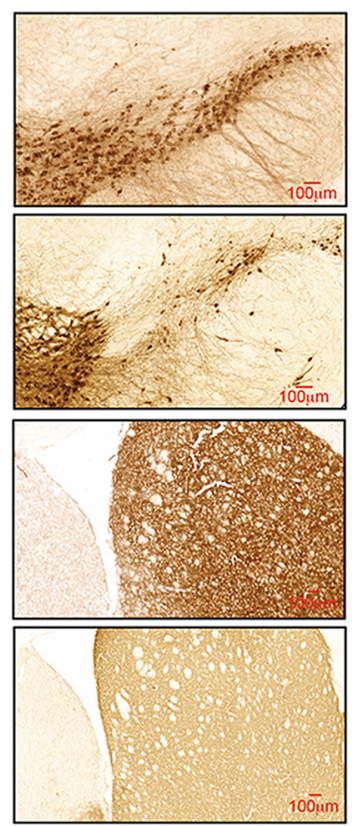

\begin{abstract}
Contralateral: uninjected
\end{abstract}
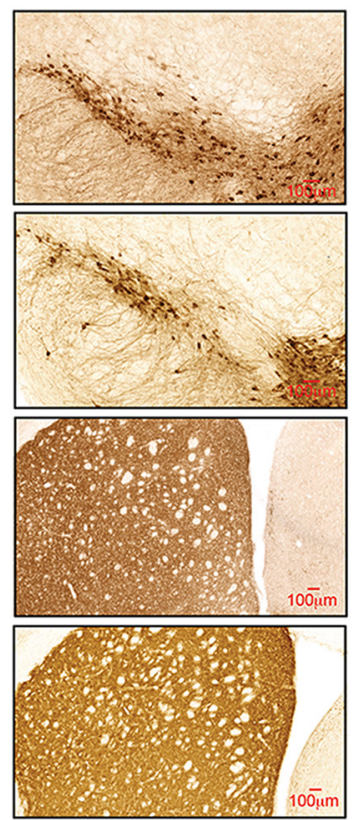

Ipsilateral: shDclk1

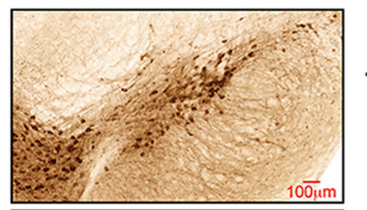

+Empty

vector

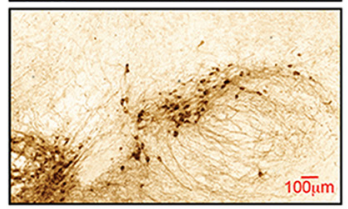

$+S N C A$

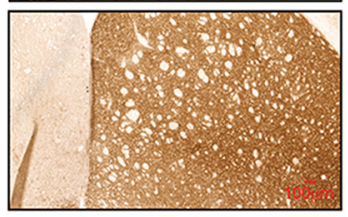

+Empty

vector

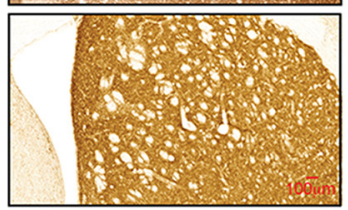

$+S N C A$

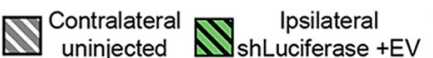

D

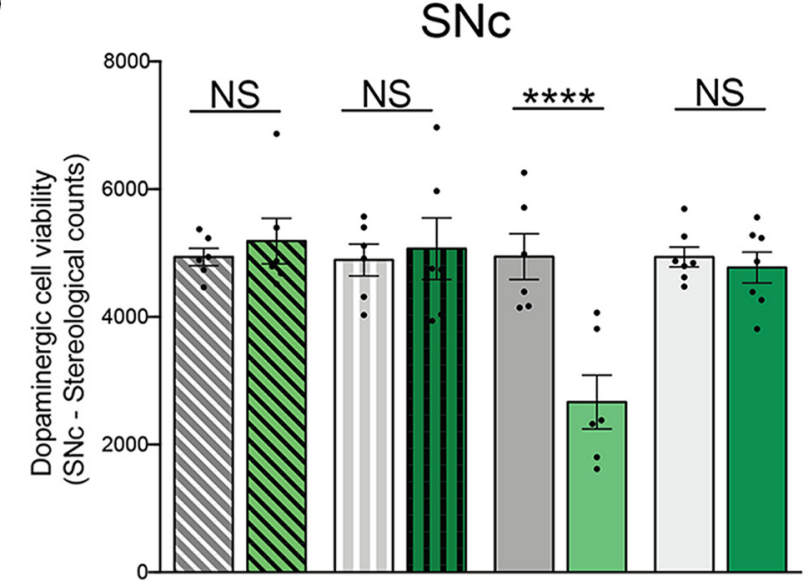

Contralateral unijected
shDclk1+EV

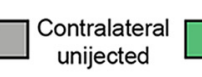

Ipsilateral

E

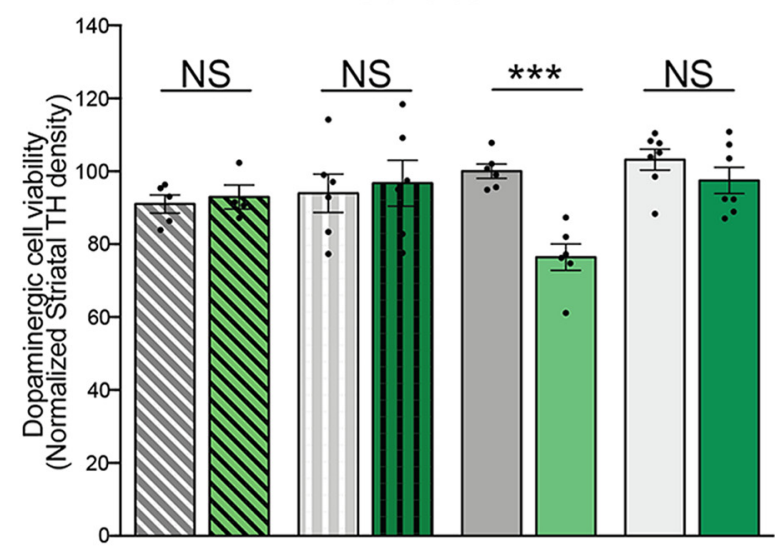

Figure 9. DClk1 knockdown rescues $\alpha$-Syn-induced dopaminergic neurotoxicity. A, Diagram of the experiment. WT mice were injected in the SNc with AAVs carrying SNCA or empty vector and shLuciferase or shDclk1. Two months later, the tissues were harvested to measure the degeneration of dopaminergic neurons and the striatal fibers. $B$, Representative images taken at $20 \times$. SNc TH staining for dopaminergic neurons of ipsilateral sections injected with shLuciferase + empty vector, shDclk1 + empty vector, shLuciferase + SNCA, or shDclk1 + SNCA compared with the corresponding contralateral uninjected sections. C, Representative images of striatal (TH-positive) fibers from the same animals taken at 20X. D, Stereological counts of dopaminergic neurons (TH-positive) in the SNC of ipsilateral sections injected with either shLuciferase + empty vector, shDclk1 + empty vector, shLuciferase + SNCA, or (Figure legend continues.) 
To test the effect of Dclk1 loss on $\alpha$-Syn-induced pathology in mice, we used neonatal intraventricular injection of AAV8 carrying a Dclk1 shRNA for widespread delivery. Because the SNCA transgene is on the $\mathrm{X}$ chromosome, we crossed Thyl- $\alpha$-Syn female mice with WT males, and injected their litters (Fig. 6A). We analyzed male mice due to the mosaicism in females arising from $\mathrm{X}$ chromosome inactivation (Disteche and Berletch, 2015). Two months after the injection, we killed the animals, dissected the posterior cortex and hippocampus, and analyzed the different $\alpha$-Syn species biochemically and histologically. We first performed IF to determine the proportion of cortical neurons infected with our virus. We found that $\sim 60 \%$ of NF-M-positive soma were also positive for YFP (indicating viral infection) (Fig. $6 B)$. Next, we confirmed Dclk1 knockdown in the posterior cortex and hippocampus via Western blot and IF (Fig. 6C,D). We found that Dclk1 knockdown robustly reduces the amount pS129- $\alpha$-Syn by Western blot (by 33\%) (Fig. 6E). However, in the context of $10 \times$ overexpression of $\alpha$-Syn, we did not detect significant changes in human or in total $\alpha$-Syn by Western blot after Dclk1 knockdown (Fig. $6 F$ ). To determine whether this was due to a lack of interaction between mouse Dclk1 and the overexpressed human $\alpha$-Syn, we pulled down endogenous Dclk1 and blotted for all three $\alpha$-Syn species. We found that pS129, human, and total $\alpha$-Syn were all able to interact with Dclk1 (Fig. $6 G$ ).

We hypothesized that this preferential effect may be due to the abundant overexpressed $\alpha$-Syn found at the presynaptic compartment that does not colocalize with Dclk1 (Fig. 2). To test this hypothesis, we first compared the colocalization of pS129 and human $\alpha$-Syn to the soma and neuronal fibers (for negative controls, see Fig. 7-1, available at https://doi.org/10.1523/ JNEUROSCI.1076-19.2019.f7-1). Using synaptophysin as a marker, we found that human $\alpha$-Syn colocalizes more strongly with neuronal fibers than pS129 $\alpha$-Syn. In contrast to this result, we found that pS129- $\alpha$-Syn colocalized more strongly with markers of neuronal soma (NF-M and YFP) than human $\alpha$-Syn (Fig. 7A). Building on this finding, we measured somatic pS129 and human $\alpha$-Syn mean fluorescence intensity (normalized to NF-M) in mice injected with either shLuciferase or shDclk1. We found that $D c l k 1$ knockdown reduced both forms of $\alpha$-Syn in neuronal soma (Fig. $7 \mathrm{~B}, \mathrm{C}$ ). Importantly, the observed reduction of pS129 $\alpha$-Syn was more dramatic than the observed reduction of human $\alpha$-Syn. Conversely, neither species of $\alpha$-Syn in neuronal fibers were affected by Dclk1 knockdown (normalized to synaptophysin) (Fig. 7D,E). Together, these results suggest than, in this context, Dclk1 knockdown preferentially reduces somatic species of $\alpha$-Syn.

We next tested whether Dclk1 knockdown can affect $\alpha$-Syninduced neurotoxicity. Since $D c l k 1$ is expressed in nigral neurons (Fig. 2C); and because the Thy1- $\alpha$-Syn model does not recapitulate the dopaminergic cell loss observed in $\mathrm{PD}$, we used a viral model of $\alpha$-Syn-induced Parkinsonism (Kirik et al., 2002; Ip et al., 2017). We first verified appropriate viral targeting of the SNc by IF (Fig. $8 A$ ), as well as Dclk1 knockdown (Fig. $8 B$ ). We also ensured that human $\alpha$-Syn overexpression caused significant loss

\section{$\leftarrow$}

(Figure legend continued.) $\quad$ shDclk1 + SNCA compared with the corresponding contralateral uninjected sections (and each other). Each data point represents a single animal ( $F=6.584$, $p<0.0001)$. $\boldsymbol{E}$, Densitometric measurement of TH fibers in the striatum from the same animals. Each data point represents a single animal $(F=4.303, p=0.0013)$. Error bars indicate SEM. One-way ANOVA followed by Dunnett's multiple-comparisons test: NS $\geq 0.05 ;{ }^{* * *} p \leq 0.001$; **** $p \leq 0.0001$ of TH-positive dopaminergic neurons in the SNc 2 months after injection (Fig. 8C,D).

Next, we performed unilateral stereotaxic injections into the SNc of WT male mice with a Flag-tagged SNCA cDNA or empty vector together with an shRNA targeting Dclk1 (shRNA) or Luciferase (shLuciferase) control (shDclk1 + empty vector vs shLuciferase + empty vector vs shDclk1 + SNCA vs shLuciferase + $S N C A$, respectively) (Fig. 9A-D). As has been previously shown (Kirik et al., 2002; Ip et al., 2017), viral overexpression of SNCA resulted in significant loss of $\mathrm{TH}$-positive dopaminergic neurons in the $\mathrm{SNc}$ as determined by unbiased stereology (Fig. 9B,D), as well as dopaminergic denervation in the striatum (Fig. 9C,E) compared with the uninjected contralateral side or animals injected with the shRNAs and an empty vector. Importantly, we found that coinjection of shDclk1 with SNCA was able to rescue these phenotypes, but coinjection with shLuciferase was not (Fig. $9 B-E)$. Together, these results suggest that $D c l k 1$ knockdown reduces phosphorylated species of $\alpha$-Syn and rescues $\alpha$-Syninduced dopaminergic neurotoxicity in the SNc in mice.

\section{DCLK1 regulates $\alpha$-Syn levels in neurons derived from a PD patient}

Having shown that Dclk1 interacts with and modulates $\alpha$-Syn levels, we next asked whether this effect is conserved in a human neuronal model derived from an individual with $\alpha$-Syn-driven PD. We derived cortical neurons from iPSCs obtained from two clones from a patient with SNCA triplication (Muenter et al., 1998; Singleton et al., 2003), an isogenic control corrected for the mutation, and the H9 line of embryonic stem cells. Using the dual-SMAD inhibition protocol, we first differentiated one of the iPSC clones (RUID:NN0000049, clone 1) as well as H9 ESCs into neural progenitor cells and then to cortical neurons. For the second SNCA triplication clone (RUID: NN0003871) (HemanAckah et al., 2017) as well as its isogenic control, we used NGN2mediated direct neuronal conversion method (Thoma et al., 2012; Zhang et al., 2013; Ho et al., 2016). We first confirmed differentiation by staining for neuronal markers ( $\beta$ III-tubulin and MAP2), as well as markers of glutamatergic (Vglut1) and GABAergic (GABA) neurons (Fig. 10A,B). Next, we confirmed that neurons from both of these SNCA triplication clones, regardless of the derivation method, carry a twofold increase in SNCA RNA compared with their respective controls (Fig. $10 C, D)$, confirming that these lines are reproducing what would be expected from the genomic duplication. We also observed that both clones contain high levels of pathologically associated pS129 $\alpha$-Syn species. Surprisingly, we found that total $\alpha$-Syn protein levels are increased approximately fivefold compared with controls in both differentiation paradigms and using both controls (Fig. 10C,D). Finally, to test the effect of DCLK1 in the context of patient neurons, we performed shRNA-mediated knockdown of DCLK1 in SNCA triplication neurons derived from clone 1 and confirmed that this intervention potently reduces both pS129 $\alpha$-Syn and total $\alpha$-Syn (Fig. 10E). Together, these data suggest that DCLK1 is a strong regulator of $\alpha$-Syn levels in patient neurons.

\section{Discussion}

The role of $\alpha$-Syn in PD and other synucleinopathies has been under intense study since its discovery $>30$ years ago (Maroteaux et al., 1988; Uéda et al., 1993; Spillantini et al., 1998). Although much has been learned about how $\alpha$-Syn oligomerizes (Pieri et al., 2016; Bengoa-Vergniory et al., 2017), aggregates (Spillantini et al., 1998), spreads (Luk et al., 2012; Mao et al., 2016; Wong and 
A

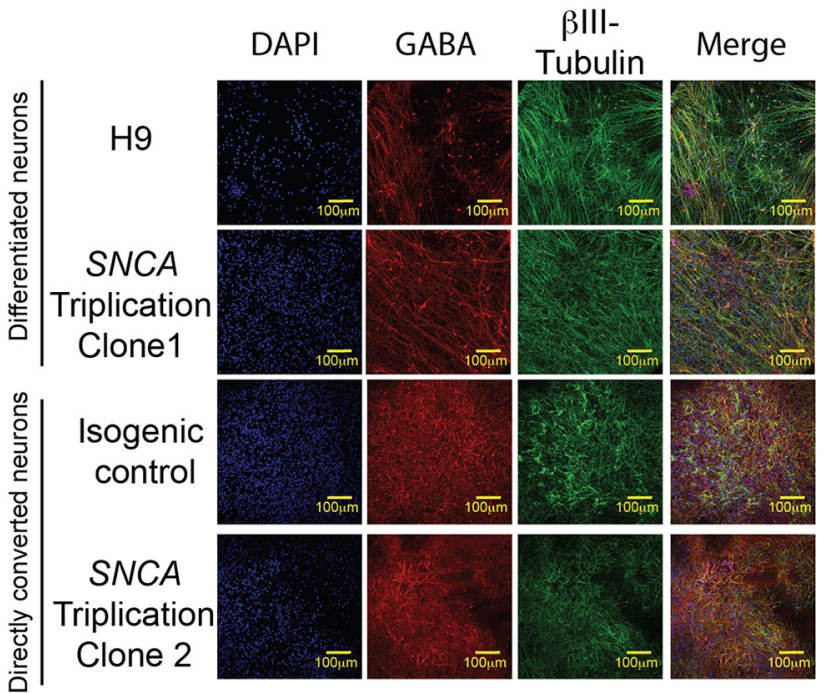

C

$$
\text { RNA }
$$
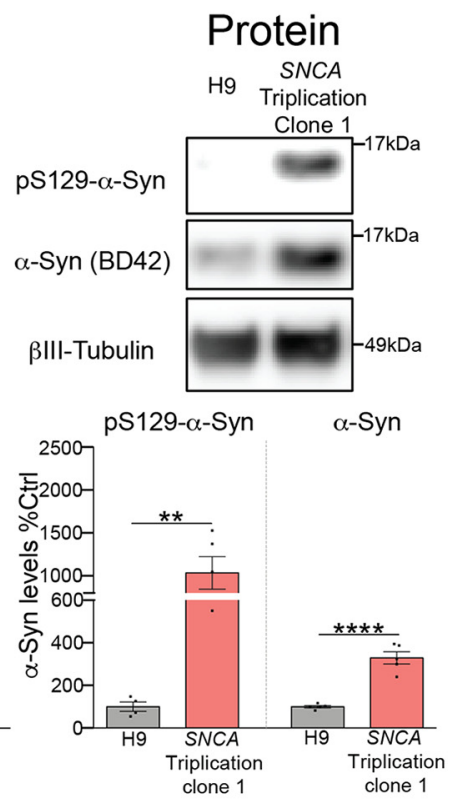

B
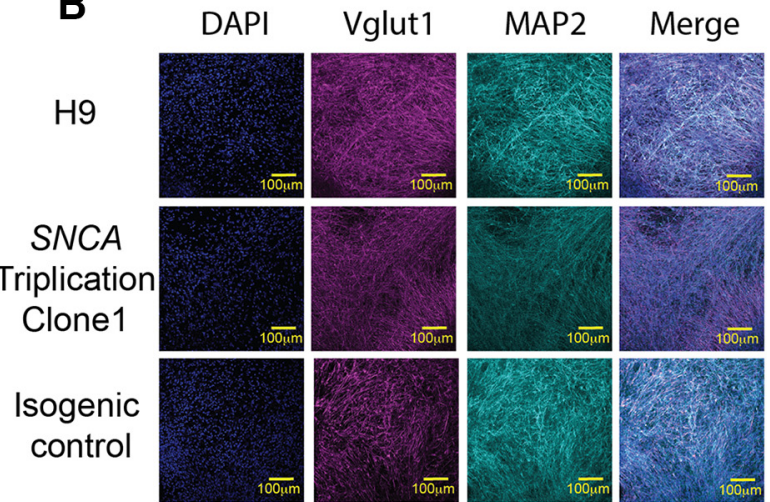

SNCA

Triplication

Clone 2
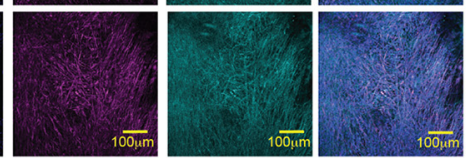

D RNA

Protein

Isogenic SNCA

control Triplication

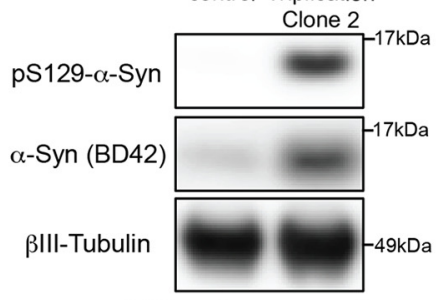

pS129- $\alpha-S y n \quad \alpha-S y n$
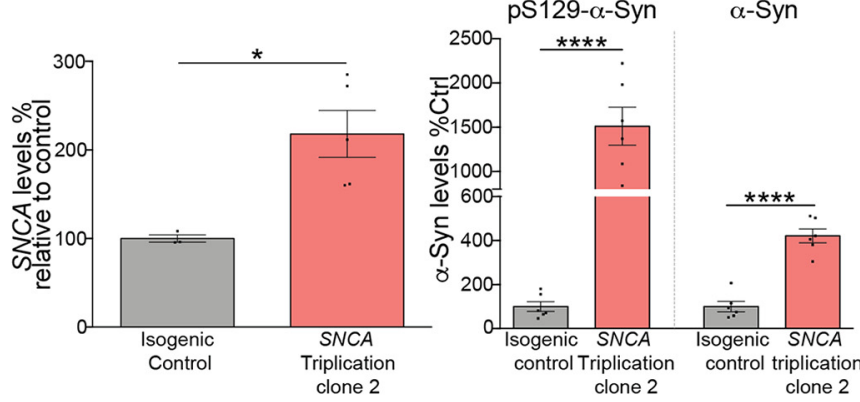
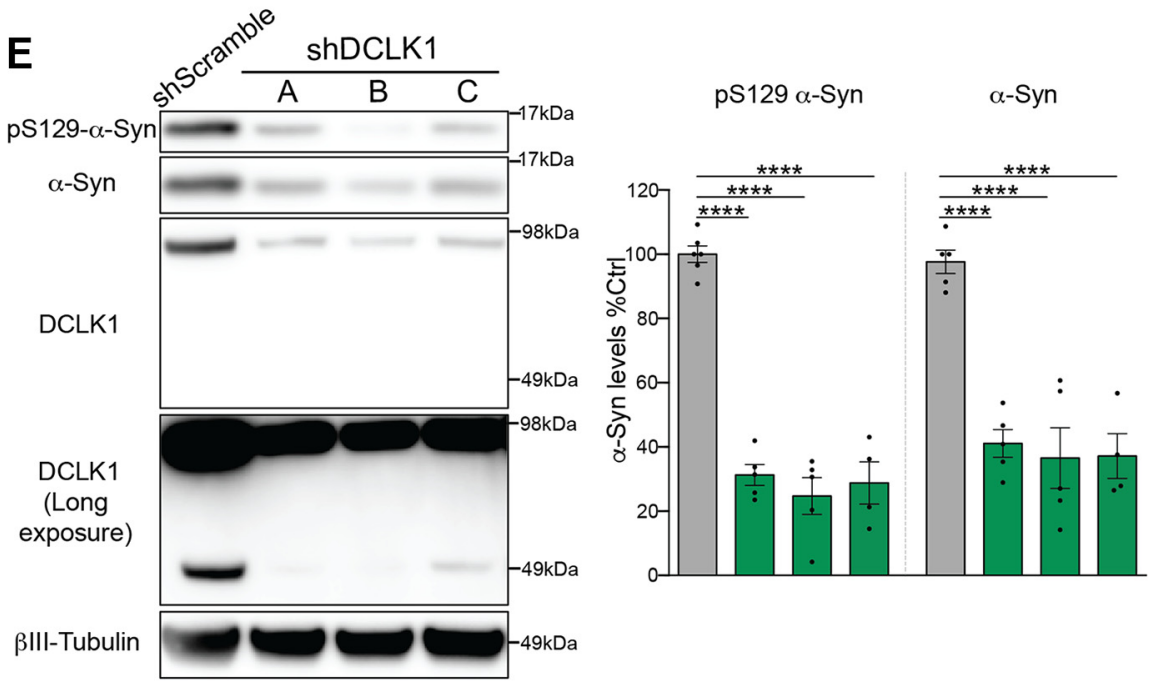

Full length DCLK1

Kinase domain

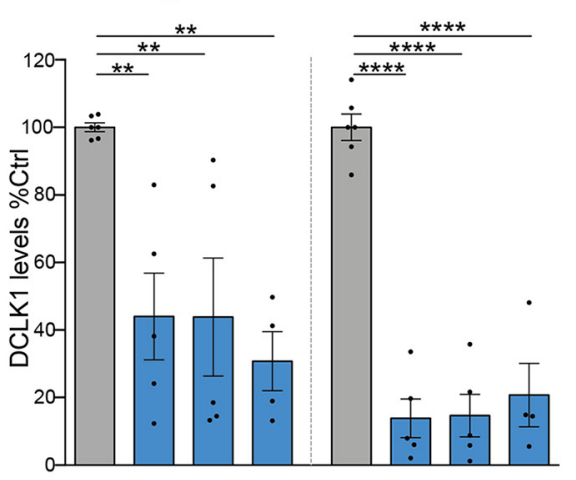

Figure 10. DCLK1 knockdown reduces $\alpha$-Syn levels in human neurons derived from a patient with SNCA triplication. $A$, Representative IF images of GABA and $\beta \| I-$-tubulin staining in H9 neurons, clone NN0000049 (SNCA Triplication clone 1), clone NN0003871 (SNCA Triplication clone 2), and its respective isogenic control. $\boldsymbol{B}$, Representative IF images of Vglut1 and MAP2 staining in H9 neurons, clone NN0000049 (SNCA Triplication clone 1), clone NN0003871 (SNCA Triplication clone 2), and its respective isogenic control. C, Measurement of RNA and protein SNCA levels of clone 1 of SNCA triplication patient neurons using qPCR and Western blotting after neuronal differentiation compared with H9 ESC-derived neurons. Both pS129 (D1RIR) and total (Figure legend continues.) 


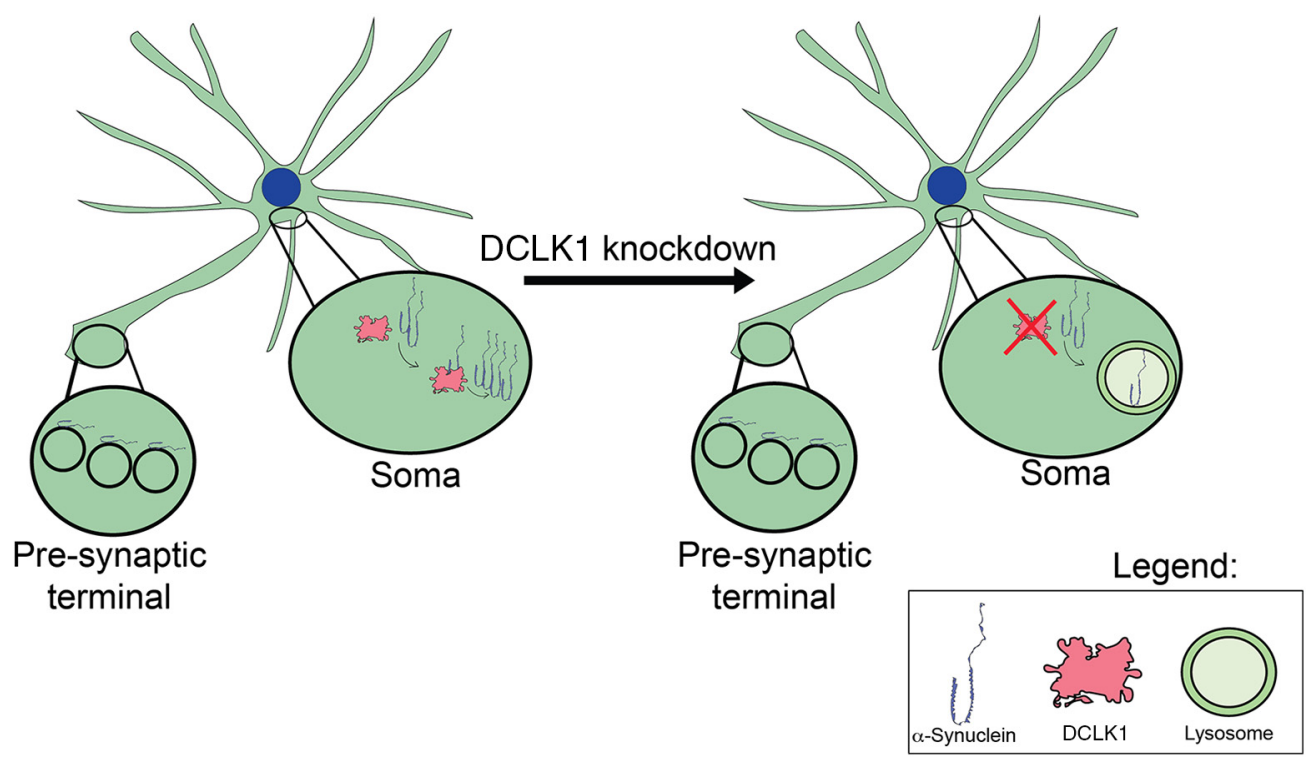

Figure 11. DCLK1 regulates somatic $\alpha$-Syn levels in a lysosomal-dependent manner. $\alpha$-Syn binds vesicles in the presynaptic compartment where DCLK1 is not present. The proteins interact in the soma were DCLK1 stabilizes $\alpha$-Syn protein levels. DCLK1 knockdown interrupts this interaction and causes a reduction in levels via lysosomal degradation.

Krainc, 2017), and causes toxicity (Martin et al., 2006; Devi et al., 2008; Mazzulli et al., 2011), relatively little is known about the molecules that control its protein levels. The fact that duplications and triplications in SNCA cause genetic forms of PD (Singleton et al., 2003; Chartier-Harlin et al., 2004; Ibáñez et al., 2004) further underscores the importance of understanding this regulation. With that in mind, recent efforts by our laboratory have set out to find regulators of $\alpha$-Syn levels (Rousseaux et al., 2016, 2018). DCLK1 emerged as one of the most promising targets for downstream validation both due to its strong and consistent modulation of endogenous $\alpha$-Syn levels in two independent screens and because of the potential of its druggability as a brainresident kinase. In this study, we sought to gain insight into the mechanism of how DCLK1 regulates $\alpha$-Syn levels. Additionally, we wanted to determine whether the knockdown of DCLK1 would be beneficial in mouse and human genetic models of synucleinopathy.

DCLK1 has been almost exclusively studied in the context of neurodevelopment. In the past, much of the research has focused on the microtubule polymerizing function (Lin et al., 2000) of the doublecortin domains that the protein possesses, how this is necessary for neuronal migration, formation of the corpus callosum (Deuel et al., 2006; Koizumi et al., 2006), and regulation of dendrite maturation (Shin et al., 2013). Apart from phosphorylation

\footnotetext{
(Figure legend continued.) $\quad \alpha$-Syn were measured (BD42) (RNA, Student's $t$ test, $t=5.35$, $p=0.0005$; protein pS129- $\alpha$-Syn, Student's $t$ test, $t=4.326, p=0.0035$; human- $\alpha$-Syn, Student's $t$ test, $t=7.815, p<0.0001)$. $D$, Measurement of RNA and protein SNCA levels of clone 2 using $\mathrm{qPCR}$ and Western blotting in directly converted neurons compared with their isogenic corrected control. Both pS129 (D1RIR) and total $\alpha$-Syn were measured (BD42) (RNA, Student's $t$ test, $t=3.333, p<0.0157$; protein pS129- $\alpha$-Syn, Student's $t$ test $, t=6.542, p<$ 0.0001 ; human- $\alpha$-Syn, Student's ttest, $t=8.138, p<0.0001)$. $E$, Western blot measurement of pS129- $\alpha$-Syn (D1RIR), total $\alpha$-Syn (BD42), and DCLK1 levels in differentiated SNCA triplication patient (clone 1) neurons after shRNA-mediated DCLK1 knockdown (pS129- $\alpha$-Syn, oneway ANOVA, $F=73.45, p<0.0001$; human- $\alpha$-Syn, one-way ANOVA, $F=21.68, p<0.0001$; full-length DCLK1, $F=7.992, p=0.0018$; kinase domain, $F=53.49, p<0.0001$ ). Each data point represents independent sets of neurons. Error bars indicate SEM. One-way ANOVA, followed by Dunnett's multiple-comparisons test: NS $\geq 0.05 ;{ }^{*} p \leq 0.05 ;{ }^{* *} p \leq 0.01 ;{ }^{* * *} p \leq$ $0.001 ; * * * 0.0001$.
}

of MAP7D1, DCX, and itself (Koizumi et al., 2017), no other function of the kinase domain of this protein has been reported. Moreover, there is currently no evidence that DCLK1 regulates the levels of any of these targets. Our data suggest that DCLK1 regulates $\alpha$-Syn post-transcriptionally via its kinase domain, independent of its catalytic activity, PEST sequence, and the DCX domains. Additionally, this effect appears to be dependent on lysosomal function. Thus, when DCLK1 is knocked down, $\alpha$-Syn protein levels decrease due to lysosomal degradation (Fig. 11). It should be noted that a wide variety of noncatalytic functions for kinases have been found previously. They include allosteric regulation of other kinases, and scaffolding for protein complexes (Kung and Jura, 2016). Despite this, how DCLK1 regulates $\alpha$-Syn levels remains elusive. Importantly, we found that endogenous $\alpha$-Syn can interact with overexpressed DCLK1. However, the interaction that was observed between endogenous proteins in vivo is very weak. It will be important in the future to further dissect how DCLK1 regulates $\alpha$-Syn levels. It is possible that DCLK1 acts as a scaffold for another protein that promotes $\alpha$-Syn stability or that DCLK1 functionally inhibits proteins that target $\alpha$-Syn to the lysosome.

It is also worth mentioning that, despite equivalent amounts of transfection, the kinase dead versions of DCLK1 seem to be more stable than their WT counterparts. This observation is perhaps not surprising given that mutations in enzymes that reduce activity are often accompanied by an increase in protein stability (Beadle and Shoichet, 2002).

To study the relationship between Dclk1 and $\alpha$-Syn in the disease context, we turned to animal and cellular models. The first, the Thy1- $\alpha$-Syn model, overexpresses WT human $\alpha$-Syn 10 -fold throughout the brain. When we knocked down Dclk1 in these mice, we were surprised to find the dramatic reduction specifically in the levels of the pS129 $\alpha$-Syn, a species of $\alpha$-Syn associated with pathology in humans with PD (Fujiwara et al., 2002; Arawaka et al., 2006). We found that this is due to the localization of the different species of $\alpha$-Syn. The transgenic $\alpha$-Syn in these mice is mostly presynaptic. In contrast pS129 $\alpha$-Syn is mostly localized to the soma, which explains why in this model of synucleinopathy, pS129 $\alpha$-Syn is drastically reduced 
with Dclk1 knockdown despite no apparent change in total $\alpha$-Syn. Interestingly, we did observe a reduction in total $\alpha$-Syn after Dclk1 knockdown in the context of the WT mouse brain. Given all of our data, we propose that Dclk1 knockdown reduces the somatic $\alpha$-Syn in this context as well, which explains why only $18 \%$ of $\alpha$-Syn is affected.

This preferential effect on somatic $\alpha$-Syn could be an attractive feature of this modulator for therapeutic purposes, as inhibiting the interaction between Dclk1 and $\alpha$-Syn could preferentially affect the $\alpha$-Syn that is mislocalized and driving toxicity, while leaving the normal function of $\alpha$-Syn unaffected. DCLK1 is also an example of how the regulation of protein levels not only depends on the cellular context, but on the context of the subcellular organelle. It should be noted, however, that we did observe a significant decrease in $\alpha$-Syn levels after DCLK1 knockdown in SNCA triplication patient neurons, which suggests that DCLK1 can regulate $\alpha$-Syn levels in a disease relevant context, albeit not in the context of massive (10-fold) $\alpha$-Syn overexpression, such as is the case for the Thy1- $\alpha$-Syn mice.

It should also be noted that we also discovered that, despite having the expected twofold increase in SNCA transcript dosage, our SNCA triplication patient lines had an approximately fivefold increase in $\alpha$-Syn protein relative to controls. This finding warrants further study and could indicate that the triplication of SNCA overwhelms the machinery controlling $\alpha$-Syn protein levels.

To study the functional effects of Dclk1 knockdown in the context of $\alpha$-Syn-induced neurotoxicity, we used a mouse viral overexpression model in which SNCA is overexpressed in the SNc. We found that Dclk1 knockdown rescues dopaminergic neuron death in this model (Fig. 9). These results highlight the therapeutic potential of targeting this interaction as modulating DCLK1 levels not only changes $\alpha$-Syn levels but shows a clear functional benefit. Another important question is whether modulating Dclk1 levels in the adult brain is safe. This is especially important because Dclk1 regulates microtubular stability (Lin et al., 2000). Previous attempts to generate Dclk1 KO mice have failed to remove the truncated transcripts coding for the kinase domain because of the large number of unique Dclk1 transcripts in the mouse brain (Deuel et al., 2006; Koizumi et al., 2006). One advantage of our approach is that our shRNA targets all forms of $D c l k 1$, and it circumvents any developmental roles of the gene because the shRNA is delivered postnatally. Importantly, although overexpression of DCLK1 results in microtubule polymerization (Lin et al., 2000), the knockdown or KO of full-length DCLK1 has been shown to affect microtubular stability only in conjunction with knockdown of other members of its protein family (DCX or DCLK2) (Deuel et al., 2006; Koizumi et al., 2006; Shin et al., 2013), which suggests that partial inhibition of Dclk1 may be safe. However, the next logical step is to conditionally knock out all transcripts of Dclk1 in the adult brain to test the safety of removing it in the mature brain in the same way we recently did for Trim28 (Rousseaux et al., 2018).

In this study, we identified a new function in the mature brain for DCLK1. Moreover, we established the feasibility of targeting DCLK1 as a regulator of $\alpha$-Syn levels, and we reveal that its reduction had the most dramatic effect on the phosphorylated and most toxic form of $\alpha$-Syn. Because there is ample evidence showing that $\alpha$-Syn levels can drive disease, lowering DCLK1 levels, in combination with other modulators of $\alpha$-Syn, is a viable diseasemodifying strategy for PD.

\section{References}

Anderson JP, de Laat R, Caccavello RJ, Walker DE, Goldstein JM, Banducci K, Barbour R, Huang J, Kling K, Lee M, Diep L, Keim PS, Shen X, Chataway T, Schlossmacher MG, Seubert P, Schenk D, Sinha S, Gai WP, Chilcote TJ (2006) Phosphorylation of ser-129 is the dominant pathological modification of $\alpha$-synuclein in familial and sporadic Lewy body disease. J Biol Chem 281:29739-29752.

Arawaka S, Wada M, Goto S, Karube H, Sakamoto M, Ren CH, Koyama S, Nagasawa H, Kimura H, Kawanami T, Kurita K, Tajima K, Daimon M, Baba M, Kido T, Saino S, Goto K, Asao H, Kitanaka C, Takashita E, et al. (2006) The role of G-protein-coupled receptor in pathogenesis of sporadic Parkinson's disease. J Neurosci 26:9227-9238.

Beadle BM, Shoichet BK (2002) Structural bases of stability-function tradeoffs in enzymes. J Mol Biol 2:285-296.

Bengoa-Vergniory N, Roberts RF, Wade-Martins R, Alegre-Abarrategui J (2017) Alpha-synuclein oligomers: a new hope. Acta Neuropathol 134:819-838.

Bondar VV, Adamski CJ, Onur TS, Tan Q, Wang L, Diaz-Garcia J, Park J, Orr HT, Botas J, Zoghbi HY (2018) PAK1 regulates ATXN1 levels providing an opportunity to modify its toxicity in spinocerebellar ataxia type 1 . Hum Mol Genet 27:2863-2873.

Brahmachari S, Ge P, Lee SH, Kim D, Karuppagounder SS, Kumar M, Mao X, Shin JH, Lee Y, Pletnikova O, Troncoso JC, Dawson VL, Dawson TM, Ko HS (2016) Activation of tyrosine kinase c-Abl contributes to alphasynuclein-induced neurodegeneration. J Clin Invest 126:2970-2988.

Burgess HA, Reiner O (2002) Alternative splice variants of doublecortinlike kinase are differentially expressed and have different kinase activities. J Biol Chem 277:17696-17705.

Burgess HA, Martinez S, Reiner O (1999) KIAA0369, doublecortin-like kinase, is expressed during brain development. J Neurosci Res 58:567-575.

Burré J, Sharma M, Südhof TC (2018) Cell biology and pathophysiology of $\alpha$-synuclein. Cold Spring Harb Perspect Med 8:a024091.

Chartier-Harlin MC, Kachergus J, Roumier C, Mouroux V, Douay X, Lincoln S, Levecque C, Larvor L, Andrieux J, Hulihan M, Waucquier N, Defebvre L, Amouyel P, Farrer M, Destée A (2004) Alpha-synuclein locus duplication as a cause of familial Parkinson's disease. Lancet 364:1167-1169.

Chesselet MF, Richter F, Zhu C, Magen I, Watson MB, Subramaniam SR (2012) A progressive mouse model of Parkinson's disease: the Thyl-aSyn ("Line 61") mice. Neurotherapeutics 9:297-314.

Clough RL, Dermentzaki G, Stefanis L (2009) Functional dissection of the $\alpha$-synuclein promoter: transcriptional regulation by ZSCAN21 and ZNF219. J Neurochem 110:1479-1490.

Crutcher E, Pal R, Naini F, Zhang P, Laugsch M, Kim J, Bajic A, Schaaf CP (2019) mTOR and autophagy pathways are dysregulated in murine and human models of Schaaf-Yang syndrome. Sci Rep 9:1-13.

Cuervo AM, Stefanis L, Fredenburg R, Lansbury PT, Sulzer D (2004) Impaired degradation of mutant $\alpha$-synuclein by chaperone-mediated autophagy. Science 305:1292-1295.

Dermentzaki G, Paschalidis N, Politis PK, Stefanis L (2016) Complex effects of the ZSCAN21 transcription factor on transcriptional regulation of $\alpha$-synuclein in primary neuronal cultures and in vivo. J Biol Chem 291: 8756-8772.

des Portes V, Pinard JM, Billuart P, Vinet MC, Koulakoff A, Carrié A, Gelot A, Dupuis E, Motte J, Berwald-Netter Y, Catala M, Kahn A, Beldjord C, Chelly J (1998) A novel CNS gene required for neuronal migration and involved in X-linked subcortical laminar heterotopia and lissencephaly syndrome. Cell 92:51-61.

Deuel TA, Liu JS, Corbo JC, Yoo SY, Rorke-Adams LB, Walsh CA (2006) Genetic interactions between doublecortin and doublecortin-like kinase in neuronal migration and axon outgrowth. Neuron 49:41-53.

Devi L, Raghavendran V, Prabhu BM, Avadhani NG, Anandatheerthavarada HK (2008) Mitochondrial import and accumulation of $\alpha$-synuclein impair complex I in human dopaminergic neuronal cultures and Parkinson disease brain. J Biol Chem 283:9089-9100.

Devine MJ, Gwinn K, Singleton A, Hardy J (2011) Parkinson's disease and $\alpha$-synuclein expression. Mov Disord 26:2160-2168.

Disteche CM, Berletch JB (2015) X-chromosome inactivation and escape. J Genet 94:591-599.

Dorsey RE, Elbaz A (2018) Global, regional, and national burden of Parkinson's disease, 1990-2016: a systematic analysis for the global burden of disease study 2016. Lancet Neurol 17:939-953.

Fellmann C, Hoffmann T, Sridhar V, Hopfgartner B, Muhar M, Roth M, Lai 
DY, Barbosa IA, Kwon JS, Guan Y, Sinha N, Zuber J (2013) An optimized microRNA backbone for effective single-copy RNAi. Cell Rep 5:1704-1713.

Fujiwara H, Hasegawa M, Dohmae N, Kawashima A, Masliah E, Goldberg MS, Shen J, Takio K, Iwatsubo T (2002) $\alpha$-Synuclein is phosphorylated in synucleinopathy lesions. Nat Cell Biol 4:160-164.

Gleeson JG, Minnerath SR, Fox JW, Allen KM, Luo RF, Hong SE, Berg MJ, Kuzniecky R, Reitnauer PJ, Borgatti R, Mira AP, Guerrini R, Holmes GL, Rooney CM, Berkovic S, Scheffer I, Cooper EC, Ricci S, Cusmai R, Crawford TO, et al. (1999) Characterization of mutations in the gene doublecortin in patients with double cortex syndrome. Ann Neurol 45: $146-153$.

Heman-Ackah SM, Manzano R, Hoozemans JJ, Scheper W, Flynn R, Haerty W, Cowley SA, Bassett AR, Wood MJ (2017) Alpha-synuclein induces the unfolded protein response in Parkinson's disease SNCA triplication iPSC-derived neurons. Hum Mol Genet 26:4441-4450.

Ho SM, Hartley BJ, Tcw J, Beaumont M, Stafford K, Slesinger PA, Brennand KJ (2016) Rapid Ngn2-induction of excitatory neurons from hiPSCderived neural progenitor cells. Methods 101:113-124.

Horesh D, Sapir T, Francis F, Wolf SG, Caspi M, Elbaum M, Chelly J, Reiner O (1999) Doublecortin, a stabilizer of microtubules. Hum Mol Genet 8:1599-1610.

Ibáñez P, Bonnet AM, Débarges B, Lohmann E, Tison F, Pollak P, Agid Y, Dürr A, Brice A (2004) Causal relation between $\alpha$-synuclein gene duplication and familial Parkinson's disease. Lancet 364:1169-1171.

Ip CW, Klaus LC, Karikari AA, Visanji NP, Brotchie JM, Lang AE, Volkmann J, Koprich JB (2017) AAV1/2-induced overexpression of A53T- $\alpha$ synuclein in the substantia nigra results in degeneration of the nigrostriatal system with Lewy-like pathology and motor impairment: a new mouse model for Parkinson's disease. Acta Neuropathol Commun 5:11.

Jiang X, Chen J, Bajić A, Zhang C, Song X, Carroll SL, Cai ZL, Tang M, Xue M, Cheng N, Schaaf CP, Li F, MacKenzie KR, Ferreon AC, Xia F, Wang MC, Maletić-Savatić M, Wang J (2017) Quantitative real-time imaging of glutathione. Nat Commun 8:16163.

Kahle PJ, Neumann M, Ozmen L, Muller V, Jacobsen H, Schindzielorz A, Okochi M, Leimer U, van Der Putten H, Probst A, Kremmer E, Kretzschmar HA, Haass C (2000) Subcellular localization of wild-type and Parkinson's disease-associated mutant $\alpha$-synuclein in human and transgenic mouse brain. J Neurosci 20:6365-6373.

Kim HJ, Na JI, Min BW, Na JY, Lee KH, Lee JH, Lee YJ, Kim HS, Park JT (2014) Evaluation of protein expression in housekeeping genes across multiple tissues in rats. Korean J Pathol 48:193-200.

Kim JY, Ash RT, Ceballos-Diaz C, Levites Y, Golde TE, Smirnakis SM, Jankowsky JL (2013) Viral transduction of the neonatal brain delivers controllable genetic mosaicism for visualising and manipulating neuronal circuits in vivo. Eur J Neurosci 37:1203-1220.

Kirik D, Rosenblad C, Burger C, Lundberg C, Johansen TE, Muzyczka N, Mandel RJ, Björklund A (2002) Parkinson-like neurodegeneration induced by targeted overexpression of $\alpha$-synuclein in the nigrostriatal system. J Neurosci 22:2780-2791.

Klisch TJ, Vainshtein A, Patel AJ, Zoghbi HY (2017) Jak2-mediated phosphorylation of atoh1 is critical for medulloblastoma growth. Elife 6:1-14.

Koizumi H, Tanaka T, Gleeson JG (2006) Doublecortin-like kinase functions with doublecortin to mediate fiber tract decussation and neuronal migration. Neuron 49:55-66.

Koizumi H, Fujioka H, Togashi K, Thompson J, Yates JR 3rd, Gleeson JG, Emoto K (2017) DCLK1 phosphorylates the microtubule-associated protein MAP7D1 to promote axon elongation in cortical neurons. Dev Neurobiol 77:493-510.

Kung JE, Jura N (2016) Structural basis for the non-catalytic functions of protein kinases. Structure 24:7-24.

Lassot I, Mora S, Lesage S, Zieba BA, Coque E, Condroyer C, Bossowski JP, Mojsa B, Marelli C, Soulet C, Tesson C, Carballo-Carbajal I, Laguna A, Mangone G, Vila M, Brice A, Desagher S (2018) The E3 ubiquitin ligases TRIM17 and TRIM41 modulate $\alpha$-synuclein expression by regulating ZSCAN21. Cell Rep 25:2484-2496.e9.

Latremoliere A Cheng L, DeLisle M, Wu C, Chew S, Hutchinson EB, Sheridan A, Alexandre C, Latremoliere F, Sheu SH, Golidy S, Omura T, Huebner EA, Fan Y, Whitman MC, Nguyen E, Hermawan C, Pierpaoli C, Tischfield MA, Wool CJ, et al. (2018) Neuronal-specific TUBB3 is not required for normal neuronal function but is essential for timely axon regeneration. Cell Rep 24:1865-1879.e9.
Lee HJ, Khoshaghideh F, Patel S, Lee SJ (2004) Clearance of $\alpha$-synuclein oligomeric intermediates via the lysosomal degradation pathway. J Neurosci 24:1888-1896.

Lin PT, Gleeson JG, Corbo JC, Flanagan L, Walsh CA (2000) DCAMKL1 encodes a protein kinase with homology to doublecortin that regulates microtubule polymerization. J Neurosci 20:9152-9161.

Lipka J, Kapitein LC, Jaworski J, Hoogenraad CC (2016) Microtubulebinding protein doublecortin-like kinase 1 (DCLK1) guides kinesin-3mediated cargo transport to dendrites. EMBO J 35:302-318.

Luk KC, Kehm V, Carroll J, Zhang B, O'Brien P, Trojanowski JQ, Lee VM (2012) Pathological $\alpha$-synuclein transmission in nontransgenic mice. Science 338:949-953.

Mahul-Mellier AL, Fauvet B, Gysbers A, Dikiy I, Oueslati A, Georgeon S, Lamontanara AJ, Bisquertt A, Eliezer D, Masliah E, Halliday G, Hantschel O, Lashuel HA (2014) C-abl phosphorylates $\alpha$-synuclein and regulates its degradation: implication for $\alpha$-synuclein clearance and contribution to the pathogenesis of Parkinson's disease. Hum Mol Genet 23:28582879.

Mao X, Ou MT, Karuppagounder SS, Kam TI, Yin X, Xiong Y, Ge P, Umanah GE, Brahmachari S, Shin JH, Kang HC, Zhang J, Xu J, Chen R, Park H, Andrabi SA, Kang SU, Gonçalves RA, Liang Y, Zhang S, et al. (2016) Pathological $\alpha$-synuclein transmission initiated by binding lymphocyteactivation gene 3. Science 353:aah3374.

Maroteaux L, Campanelli JT, Scheller RH (1988) Synuclein: a neuronspecific protein localized to the nucleus and presynaptic nerve terminal. J Neurosci 8:2804-2815.

Martin LJ, Pan Y, Price AC, Sterling W, Copeland NG, Jenkins NA, Price DL, Lee MK (2006) Parkinson's disease $\alpha$-synuclein transgenic mice develop neuronal mitochondrial degeneration and cell death. J Neurosci 26:4150.

Mazzulli JR, Xu YH, Sun Y, Knight AL, McLean PJ, Caldwell GA, Sidransky E, Grabowski GA, Krainc D (2011) Gaucher disease glucocerebrosidase and $\alpha$-synuclein form a bidirectional pathogenic loop in synucleinopathies. Cell 146:37-52.

Muenter MD, Forno LS, Hornykiewicz O,Kish SJ, Maraganore DM, Caselli RJ, Okazaki H, Howard FM Jr, Snow BJ, Calne DB (1998) Hereditary form of Parkinsonism-dementia. Ann Neurol 43:768-781.

Mittal S, Bjørnevik K, Im DS, Flierl A, Dong X, Locascio JJ, Abo KM, Long E, Jin M, Xu B, Xiang YK, Rochet JC, Engeland A, Rizzu P, Heutink P, Bartels T, Selkoe DJ, Caldarone BJ, Glicksman MA, Khurana V, et al. (2017) $\beta 2$-Adrenoreceptor is a regulator of the $\alpha$-synuclein gene driving risk of Parkinson's disease. Science 357:891-898.

Oueslati A, Schneider BL, Aebischer P, Lashuel HA (2013) Polo-like kinase 2 regulates selective autophagic $\alpha$-synuclein clearance and suppresses its toxicity in vivo. Proc Natl Acad Sci U S A 110:E3945-E3954.

Patel O, Dai W, Mentzel M, Griffin MD, Serindoux J, Gay Y, Fischer S, Sterle S, Kropp A, Burns CJ, Ernst M, Buchert M, Lucet IS (2016) Biochemical and structural insights into doublecortin-like kinase domain 1. Structure 24:1550-1561.

Pelossof R, Fairchild L, Huang CH, Widmer C, Sreedharan VT, Sinha N, Lai DY, Guan Y, Premsrirut PK, Tschaharganeh DF, Hoffmann T, Thapar V, Xiang Q, Garippa RJ, Rätsch G, Zuber J, Lowe SW, Leslie CS, Fellmann C (2017) Prediction of potent shRNAs with a sequential classification algorithm. Nat Biotechnol 35:350-353.

Pfaffl MW (2001) A new mathematical model for relative quantification in real-time RT-PCR. Nucleic Acids Res 29:e45.

Pieri L, Madiona K, Melki R (2016) Structural and functional properties of prefibrillar $\alpha$-synuclein oligomers. Sci Rep 6:24526.

Rockenstein E, Mallory M, Hashimoto M, Song D, Shults CW, Lang I, Masliah E (2002) Differential neuropathological alterations in transgenic mice expressing $\alpha$-synuclein from the platelet-derived growth factor and thy-1 promoters. J Neurosci Res 68:568-578.

Rott R, Szargel R, Haskin J, Bandopadhyay R, Lees AJ, Shani V, Engelender S (2011) $\alpha$-Synuclein fate is determined by USP9X-regulated monoubiquitination. Proc Natl Acad Sci U S A 108:18666-18671.

Rousseaux MW, de Haro M, Lasagna-Reeves CA, de Maio A, Park J, JafarNejad P, Al-Ramahi I, Sharma A, See L, Lu N, Vilanova-Velez L, Klisch TJ, Westbrook TF, Troncoso JC, Botas J, Zoghbi HY (2016) TRIM28 regulates the nuclear accumulation and toxicity of both alpha-synuclein and tau. Elife 5:e19809.

Rousseaux MW, Vázquez-Vélez GE, Al-Ramahi I, Jeong HH, Bajic A, Revelli JP, Ye H, Phan ET, Deger JM, Perez AM, Kim JY, Lavery LA, Xu Q, Li MZ, 
Kang H, Kim JJ, Shulman JM, Westbrook TF, Elledge SJ, Liu Z, et al. (2018) A druggable genome screen identifies modifiers of $\alpha$-synuclein levels via a tiered cross-species validation approach. J Neurosci 38: 9286-9301.

Scherzer CR, Grass JA, Liao Z, Pepivani I, Zheng B, Eklund AC, Ney PA, Ng J, McGoldrick M, Mollenhauer B, Bresnick EH, Schlossmacher MG (2008) GATA transcription factors directly regulate the Parkinson's diseaselinked gene $\alpha$-synuclein. Proc Natl Acad Sci U S A 105:10907-10912.

Schindelin J, Arganda-Carreras I, Frise E, Kaynig V, Longair M, Pietzsch T, Preibisch S, Rueden C, Saalfeld S, Schmid B, Tinevez JY, White DJ, Hartenstein V, Eliceiri K, Tomancak P, Cardona A (2012) Fiji: an opensource platform for biological-image analysis. Nat Methods 9:676-682.

Shang L, Kwon YG, Nandy S, Lawrence DS, Edelman AM (2003) Catalytic and regulatory domains of doublecortin kinase-1. Biochemistry 42:21852194.

Shin E, Kashiwagi Y, Kuriu T, Iwasaki H, Tanaka T, Koizumi H, Gleeson JG, Okabe S (2013) Doublecortin-like kinase enhances dendritic remodelling and negatively regulates synapse maturation. Nat Commun 4:1414-1440.

Silverman MA, Benard O, Jaaro H, Rattner A, Citri Y, Seger R (1999) CPG16, a novel protein serine/threonine kinase downstream of cAMPdependent protein kinase. J Biol Chem 274:2631-2636.

Singleton AB, Farrer M, Johnson J, Singleton A, Hague S, Kachergus J, Hulihan M, Peuralinna T, Dutra A, Nussbaum R, Lincoln S, Crawley A, Hanson M, Maraganore D, Adler C, Cookson MR, Muenter M, Baptista M, Miller D, Blancato J, et al. (2003) Alpha-synuclein locus triplication causes Parkinson's disease. 302:841.

Soldner F, Stelzer Y, Shivalila CS, Abraham BJ, Latourelle JC, Barrasa MI, Goldmann J, Myers RH, Young RA, Jaenisch R (2016) Parkinsonassociated risk variant in distal enhancer of $\alpha$-synuclein modulates target gene expression. Nature 533:95-99.

Spillantini MG, Crowther RA, Jakes R, Hasegawa M, Goedert M (1998)
$\alpha$-Synuclein in filamentous inclusions of Lewy bodies from Parkinson's disease and dementia with Lewy bodies. Proc Natl Acad Sci U S A 95:6469-6473.

Thoma EC, Wischmeyer E, Offen N, Maurus K, Sirén AL, Schartl M, Wagner TU (2012) Ectopic expression of neurogenin 2 alone is sufficient to induce differentiation of embryonic stem cells into mature neurons. PLoS One 7:e38651.

Tofaris GK, Kim HT, Hourez R, Jung JW, Kim KP, Goldberg AL (2011) Ubiquitin ligase Nedd 4 promotes $\alpha$-synuclein degradation by the endosomal-lysosomal pathway. Proc Natl Acad Sci U S A 108:1700417009.

Uéda K, Fukushima H, Masliah E, Xia Y, Iwai A, Yoshimoto M, Otero DA, Kondo J, Ihara Y, Saitoh T (1993) Molecular cloning of cDNA encoding an unrecognized component of amyloid in Alzheimer disease. Proc Natl Acad Sci U S A 90:11282-11286.

Unni VK, Weissman TA, Rockenstein E, Masliah E, McLean PJ, Hyman BT (2010) In vivo imaging of $\alpha$-synuclein in mouse cortex demonstrates stable expression and differential subcellular compartment mobility. PLoS One 5:e10589.

Vogiatzi T, Xilouri M, Vekrellis K, Stefanis L (2008) Wild type $\alpha$-synuclein is degraded by chaperone-mediated autophagy and macroautophagy in neuronal cells. J Biol Chem 283:23542-23556.

Withers GS, George JM, Banker GA, Clayton DF (1997) Delayed localization of synelfin (synuclein, NACP) to presynaptic terminals in cultured rat hippocampal neurons. Brain Res Dev Brain Res 99:87-94.

Wong YC, Krainc D (2017) $\alpha$-Synuclein toxicity in neurodegeneration: mechanism and therapeutic strategies. Nat Med 23:1-13.

Zhang Y, Pak C, Han Y, Ahlenius H, Zhang Z, Chanda S, Marro S, Patzke C, Acuna C, Covy J, Xu W, Yang N, Danko T, Chen L, Wernig M, Südhof TC (2013) Rapid single-step induction of functional neurons from human pluripotent stem cells. Neuron 78:785-798. 